\title{
Phytosynthesis of Silver and Gold Nanoparticles Using the Hot Water Extract of Mixed Woodchip Powder and Their Antibacterial Efficacy
}

\author{
Min-Ho Joe, ${ }^{1,2}$ Hyun-Tak Jeong, ${ }^{1,3}$ Hyung-Min Lee, ${ }^{1}$ Hae-Jun Park, ${ }^{1}$ \\ Dong-Ho Kim, ${ }^{1}$ Don-Hee Park, ${ }^{3,4}$ and Suk Bai ${ }^{5}$ \\ ${ }^{1}$ Department of Biotechnology, Korea Atomic Energy Research Institute, Jeongeup 56212, Republic of Korea \\ ${ }^{2}$ School of Biological Sciences and Biotechnology, Chonnam National University, Gwangju 61186, Republic of Korea \\ ${ }^{3}$ Interdisciplinary Program of Graduate School for Bioenergy and Biomaterials, Chonnam National University, \\ Gwangju 61186, Republic of Korea \\ ${ }^{4}$ Department of Biotechnology and Bioengineering, Chonnam National University, Gwangju 61186, Republic of Korea \\ ${ }^{5}$ Department of Biological Sciences, College of Natural Sciences, Chonnam National University, Gwangju 61186, Republic of Korea
}

Correspondence should be addressed to Suk Bai; sukbai@jnu.ac.kr

Received 6 April 2017; Accepted 28 June 2017; Published 11 September 2017

Academic Editor: Jorge Pérez-Juste

Copyright (C) 2017 Min-Ho Joe et al. This is an open access article distributed under the Creative Commons Attribution License, which permits unrestricted use, distribution, and reproduction in any medium, provided the original work is properly cited.

This study investigates the phytosynthesis, characterization, and antibacterial efficacy of silver and gold nanoparticles (NPs) produced using the hot water extract of mixed woodchip powder. The woodchip extract (WCE) was successfully used as both a reducing and stabilizing agent for the phytosynthesis of both crystalline metal NPs. The effects of different physicochemical factors affecting the formation of the metal NPs including reaction $\mathrm{pH}$, concentration of the precursor metal salts, amount of WCE, and external energy input were evaluated. The characterization of the metal NPs was performed by transmission electron microscopy, selected area electron diffraction (SAED), energy dispersive X-ray (EDX) spectroscopy, and X-ray diffraction (XRD) pattern analysis. In addition, the antibacterial efficacy of the phytosynthesized NPs was measured. The AgNPs showed clear antibacterial activity against four representative bacterial strains. However, the AuNPs did not exhibit bactericidal activity, probably due to their surface modifications and relatively large size. These results suggest that the phytosynthesis of the metal NPs using WCE is highly efficient, and its convenience makes it suitable for use in large-scale production.

\section{Introduction}

Nanoparticles (NPs) are of great scientific interest due to their extremely small size and large surface-to-volume ratio, which contribute to both physical and chemical differences between their characteristics and those of larger particles of the bulk material [1]. These NPs have been used in diverse fields, such as the biomedical, agricultural, textile, food, optical, and electronic industries [1-3]. For instance, metal NPs are widely used in biomedicine as fluorescent biological labels $[4,5]$ and as gene or drug delivery systems [6,7], as well as for the detection of pathogens [8], MRI contrast enhancement agents [9], and so on. NPs have been generally produced by a number of physical and chemical methods. Attrition and pyrolysis are the most commonly used physical methods to fabricate metal NPs. However, their production rates are quite low, and they are expensive. Another drawback of physical synthesis is the considerable energy required to maintain the high pressure and temperature used in the synthesis procedures, and NPs with a narrow size distribution are often difficult to achieve [1]. In chemical synthesis, NPs are usually grown in a liquid mixture containing various reducing and stabilizing agents. Although the chemical methods are inexpensive for large-scale production, they typically use toxic chemicals and nonpolar solvents during synthesis and generate hazardous by-products, thus precluding their applications in clinical and biomedical fields. For these reasons, there has been a growing 
need to develop high-yield, nontoxic, reliable, biocompatible, low-cost, and eco-friendly methods to synthesize NPs.

Knowing the importance of emerging eco-friendly NP synthesis methods, many researchers have turned to using biological materials for NP synthesis [10]. The goal of green synthesis is to use whole or partial materials from organisms as bioengineers or raw materials for producing novel and valuable NPs. In recent years, green synthetic approaches to synthesizing NPs have emerged as a promising field of nanotechnology to overcome the drawbacks of the conventional physical and chemical methods for NP production. Microorganisms are known to have an innate potential to produce metal NPs [11], and a great deal of effort has been devoted to the biosynthesis of metal NPs using bacteria [12], fungi [13], actinomycetes [14], yeast [15], and viruses [16]. In addition, phytosynthesis utilizing plant biomass or extracts as biological factories has also gained considerable attention because plants are generally inexpensive, abundant, and nontoxic [17]. Compared to microbial synthesis, phytosynthesis is usually simpler because it avoids complex multistep processes such as microbial isolation, cultivation and maintenance, and preparation of enzymes. Therefore, phytosynthesis is a very rapid, cost-effective green approach with high potential for large-scale production [18]. Moreover, NP synthesis is known to be faster when using plant materials than when using microorganisms [19]. Plants generally synthesize a broad range of metabolites, which can be used as reducing and capping agents for NP synthesis. However, their detailed mechanism is yet to be fully understood. According to previous reports, various plant materials have been shown to have substantial potential for metal NP synthesis $[1,3,17,19$, 20]. Whole plant extracts or specific parts of diverse plants have been used to synthesize metal NPs. For example, AuNPs have been successfully synthesized using leaves from Aloe vera [21], Eucalyptus camaldulensis, Pelargonium roseum, Azadirachta indica [22], and Stevia rebaudiana [23]. Similarly, synthesis of metal NPs using various parts of plants such as fruit, latex, seeds, bark, flowers, and root stems has been extensively studied thus far [24].

Woodchips are one of the largest lignocellulosic plant biomasses on Earth, and they are produced all over the world as forestry residues and wood waste. Typically, they are used as pulp for paper, organic mulch, growing media for mushrooms, and renewable energy sources for biofuels. In this report, we demonstrated that woodchip extract (WCE) could be efficiently used to synthesize metal NPs when the process was properly optimized.

\section{Materials and Methods}

\subsection{Materials}

2.1.1. Bacterial Strains and Culture Condition. Escherichia coli, Salmonella enterica serovar Typhimurium LT2, Bacillus subtilis, and Staphylococcus aureus were used to evaluate the antimicrobial activity of the as-synthesized metal NPs. Bacterial cells were grown in Luria-Bertani (LB) medium (1\% tryptone, $0.5 \%$ yeast extract, and $0.5 \% \mathrm{NaCl}$ ) at $37^{\circ} \mathrm{C}$. For liquid cultivation, bacterial cells were aerobically grown in an orbital shaker (Jeio Tech, Daejeon, Republic of Korea) at $37^{\circ} \mathrm{C}$ with agitation $(120 \mathrm{rpm})$.

2.1.2. Woodchips and Chemicals. Barkless mixed woodchips were purchased from a local forestry company. Before experiments, the chopped $(\sim 7 \mathrm{~cm})$ barkless woodchips were thoroughly washed with tap water three times and washed again three times with deionized (DI) water to remove extraneous matter. The washed woodchips were dried in an oven (Jeio Tech) at $70^{\circ} \mathrm{C}$ until a constant weight was achieved. The dried woodchips were ground to pass through a $420 \mu \mathrm{m}$ sieve using a pulverizer (Korea Medi, Daegu, Republic of Korea) and then packed in a polystyrene bag for further use. Pure chloroauric acid was purchased from Sigma-Aldrich (St. Louis, MO, USA). Pure silver nitrate was purchased from Daejung Chemicals \& Metals Co. (Gyeonggi-do, Republic of Korea).

2.2. Compositional Analysis of the Woodchips. The composition of the woodchip powder was analyzed by following a two-stage acid hydrolysis protocol developed by the National Renewable Energy Laboratory. Briefly, each sample was subjected to hydrolysis with $72 \%$ sulfuric acid at $30^{\circ} \mathrm{C}$ for $1 \mathrm{~h}$ and then hydrolysis with $3 \%$ sulfuric acid at $121^{\circ} \mathrm{C}$ for $1 \mathrm{~h}$. The autoclaved hydrolysis solution was neutralized to a $\mathrm{pH}$ of 6.0 using calcium carbonate, and the solution was then vacuum filtered. The sugars released by acid hydrolysis were quantified on a high-performance liquid chromatography (HPLC) system (Agilent 1200, Agilent Technologies, Santa Clara, CA, USA) equipped with a refractive index detector (Agilent 1260) and a Bio-Rad Aminex HPX-87P column (Bio-Rad Laboratories, Hercules, CA, USA) was used with HPLC-grade water at a flow rate of $0.6 \mathrm{~mL} / \mathrm{min}$ at $65^{\circ} \mathrm{C}$. All of the samples were filtered through a $0.20 \mathrm{~mm}$ filter and diluted with an eluent before analysis on HPLC. Various concentrations of the pure monomeric sugar were used for standards. The water content was measured as the weight loss from $1 \mathrm{~g}$ of woodchip powder dried at $105^{\circ} \mathrm{C}$ to a constant weight. The acid-insoluble lignin (Klason lignin) content was defined as the weight of ash-free, oven-dried filter cake dried at $105^{\circ} \mathrm{C}$ to a constant weight. The elemental composition of the woodchip powder was determined using an inductively coupled plasma mass spectrometer (ICP-MS 7500, Agilent Technologies).

2.3. Preparation of the Woodchip Extract. The woodchip powder $(5 \%, w / v)$ was added to the appropriate volume of DI water and autoclaved at $121^{\circ} \mathrm{C}$ for $20 \mathrm{~min}$. Then, the aqueous solution was separated by centrifugation at 4,000 rpm for $10 \mathrm{~min}$. The supernatant was filtered through a GF/C grade glass fiber filter (GE Healthcare, Little Chalfont, UK) and then filtered again through a $0.45 \mu \mathrm{m}$ filter (Pall Corporation, Port Washington, NY, USA), and the filtrate was used for the metal NP synthesis.

2.4. Effects of Physicochemical Factors on the Phytosynthesis of the AgNPs. The potential effects of the reaction parameters on the synthesis of NPs such as the $\mathrm{pH}$, concentration of the precursor metal salts, amount of WCE, and external energy 
input were studied by varying one parameter at a time while keeping the others constant. Firstly, the effect of the $\mathrm{AgNO}_{3}$ concentrations was determined in the dark with the inherent $\mathrm{pH}$ condition while maintaining a constant reaction temperature $\left(25^{\circ} \mathrm{C}\right)$ and WCE concentration (1\%, w/v). Secondly, the $\mathrm{pH}$ of the WCE was varied while the concentrations of $\mathrm{AgNO}_{3}(10 \mathrm{mM})$ and $\mathrm{WCE}(1 \%, \mathrm{w} / \mathrm{v})$ and the reaction temperature $\left(25^{\circ} \mathrm{C}\right)$ were kept constant. The $\mathrm{pH}$ was adjusted using $\mathrm{NaOH}$ or $\mathrm{HCl}$ and the reaction was performed in the dark. Thirdly, the effect of the WCE concentration was studied in the dark while maintaining the other parameters as constant $\left(10 \mathrm{mM} \mathrm{AgNO}, \mathrm{pH} \mathrm{13}\right.$, and $\left.25^{\circ} \mathrm{C}\right)$. Fourthly, the effect of heat was evaluated in the dark with the other parameters being constant $\left(10 \mathrm{mM} \mathrm{AgNO}_{3}, \mathrm{pH} 13\right.$, and $5 \%$ WCE). Lastly, to evaluate the effect of the light energy input, different strengths of light energy irradiated the mixtures using an equal ratio of warm and cool light-emitting diodes (LEDs), while all the other parameters were fixed $\left(25^{\circ} \mathrm{C}, \mathrm{pH}\right.$ 13 , and $10 \mathrm{mM} \mathrm{AgNO}_{3}$, and 5\% WCE). The light intensity was measured using an LI-250A light meter (LI-COR Biosciences, Lincoln, NE, USA). The phytoreduction of the silver ions was confirmed by visually observing a color change in the reaction mixture. In addition, the optimum condition for each parameter was chosen by measuring changes in the surface plasmon resonance (SPR) band over time using a UVVis spectrophotometer (Biochrom, Cambridge, UK).

\subsection{Effects of Physicochemical Factors on the Phytosynthesis} of the AuNPs. The effects of the reaction parameters on the phytosynthesis of AuNPs were determined similar to the method described in Section 2.4. The optimum concentration of $\mathrm{HAuCl}_{4}$ was determined firstly under the same conditions. Secondly, the $\mathrm{pH}$ of the WCE was assessed in the dark while keeping the other parameters constant $\left(0.5 \mathrm{mM} \mathrm{HAuCl}_{4}, 1 \%\right.$ $\mathrm{WCE}$, and $25^{\circ} \mathrm{C}$ ). Thirdly, the effect of the WCE concentration was measured in the dark while keeping the other parameters constant $\left(0.5 \mathrm{mM} \mathrm{HAuCl}_{4}, \mathrm{pH} 7\right.$, and $\left.25^{\circ} \mathrm{C}\right)$. Fourthly, the effect of heat was investigated in the dark with constant

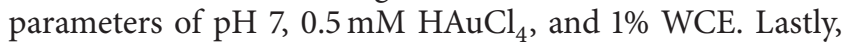
all parameters were fixed at $25^{\circ} \mathrm{C}, \mathrm{pH} 7,0.5 \mathrm{mM} \mathrm{HAuCl}_{4}$, and $1 \%$ WCE, whereas different strengths of light energy were irradiated using an equal ratio of warm and cool LEDs. The optimum condition for each parameter was determined similar to the method in Section 2.4.

2.6. Characterization of the As-Phytosynthesized NPs. Before characterization, reaction mixtures containing the metal NPs were purified at room temperature by dialysis against $3 \mathrm{~L}$ of DI water for 3 days to remove any remaining metal ions. The dialysis membrane (Spectra/Por 3 Dialysis Membrane, $3.5 \mathrm{kD}$ MWCO) used for purification was purchased from Spectrum Laboratories, Inc. (Rancho Dominguez, CA, USA). The purification process was completed by another dialysis step against DI water for 3 days and filtration through a $0.45 \mu \mathrm{m}$ filter (Pall Corporation) after $1 \mathrm{~h}$ of sonication.

High-resolution transmission electron microscopy (HRTEM) images, energy dispersive X-ray spectroscopy (EDX) line profiles, and selected area electron diffraction (SAED) patterns of the as-synthesized metal NPs were recorded using a FE-TEM Tecnai G $^{2}$ F20 with an EDX detector (FEI, Tokyo, Japan) operated at $200 \mathrm{kV}$ in the low-dose mode and a Gatan Digital Micrograph version 2.32 (Gatan Inc., Pleasanton, CA, USA). Specimens for TEM characterization were prepared directly from the reaction mixture by dropping $10 \mu \mathrm{L}$ of the sample onto lacey carbon-coated copper grids and allowing them to dry under ambient conditions. The particle size distribution was determined by measuring the diameter of 100 NPs in the TEM images.

The atomic concentration of NPs in the reaction mixture was determined using the ICP-MS (Agilent Technologies) before the following measurement. The purified NP solution was digested using a Multiwave 3000 digestion unit (Anton Paar, Austria). For the digestion, $0.8 \mathrm{~mL}$ of NP solution was placed in $100 \mathrm{~mL}$ polytetrafluoroethylene-tetrafluoroethylene (PTFE-TFM) digestion vessels and $7.2 \mathrm{~mL}$ of nitric acid (60\%) was added. The vessels were radiated for $20 \mathrm{~min}$ at $700 \mathrm{~W}$ and for $15 \mathrm{~min}$ at $1,100 \mathrm{~W}$. Concentrations of the metal NPs were used to determine the conversion yield of the metal NPs based on

$$
\begin{aligned}
& \text { Conversion yield (\%) } \\
& =\frac{[\text { Metal NPs synthesized }]}{[\text { Theoretical metal NPs }]} \times 100 \%,
\end{aligned}
$$

where [Metal NPs synthesized] was obtained from the ICPMS results and [Theoretical metal NPs] was obtained based on stoichiometric calculations.

The average conversion yield of the as-synthesized metal NPs was determined by measuring the concentration of the NPs from three independently dialyzed samples.

To determine the exact crystallinity, high-resolution Xray diffraction (XRD, PANalytical X'Pert Pro MRD, PANalytical, Holland) with $\mathrm{Cu} / \mathrm{K} \alpha$ radiation $(\lambda=1.5406 \AA)$ was performed. For the XRD studies, samples were prepared by drop-coating the NP solution on a silicon wafer, and the generator was operated at a voltage of $40 \mathrm{kV}$ and a current of $30 \mathrm{~mA}$. XRD measurements were recorded in the range $10^{\circ} \leqq$ $2 \theta \leqq 90^{\circ}$.

2.7. Measurement of the Antibacterial Activity. The antibacterial activity of the synthesized metal NPs against two Gramnegative and two Gram-positive bacteria was measured by the disk diffusion method. The tested bacterial strains were grown in LB broth at $37^{\circ} \mathrm{C}$ with agitation $(200 \mathrm{rpm})$ for $24 \mathrm{~h}$. Exponentially grown cells $\left(10^{7} \mathrm{CFU} / \mathrm{mL}\right)$ were uniformly spread onto the surface of the LB agar medium. A sterile paper disc $(8 \mathrm{~mm})$ was placed on the inoculated medium and impregnated with $50 \mu \mathrm{l}$ of the purified NPs with different concentrations. The agar plates prepared as described above were incubated at $37^{\circ} \mathrm{C}$, and a clear zone formed after 2 days.

\section{Results and Discussion}

3.1. Compositional and Elemental Analyses of the Mixed Woodchip Powder. Reportedly, plant biomass or extracts have been successfully exploited for the biosynthesis of NPs [24]. The reducing and stabilizing agents in metal NP synthesis can be any molecules that can provide reducing power 
TABLE 1: Composition analysis of mixed woodchip powder.

\begin{tabular}{lcc}
\hline & Content $(w / w, \%)$ & SD $(w / w, \%)$ \\
\hline Glucose & 43.17 & 3.29 \\
Mannose & 10.78 & 1.82 \\
Xylose & 4.1 & 0.82 \\
Galactose & 1.85 & 0.23 \\
Arabinose & 0.74 & 0.15 \\
Klason lignin & 27.55 & 3.65 \\
Water & 10.12 & 2.12 \\
\hline
\end{tabular}

SD; standard deviation.

TABLE 2: Elemental analysis of mixed woodchip powder.

\begin{tabular}{lcc}
\hline Element & Content $(\mathrm{mg} / \mathrm{kg})$ & $\mathrm{SD}(\mathrm{mg} / \mathrm{kg})$ \\
\hline $\mathrm{Al}$ & 16.51 & 3.92 \\
$\mathrm{As}$ & $\mathrm{ND}$ & $\mathrm{ND}$ \\
$\mathrm{Ca}$ & 446.37 & 41.51 \\
$\mathrm{Cd}$ & $\mathrm{ND}$ & $\mathrm{ND}$ \\
$\mathrm{Cr}$ & $\mathrm{ND}$ & $\mathrm{ND}$ \\
$\mathrm{Cu}$ & 0.15 & 0.02 \\
$\mathrm{Fe}$ & 90.58 & 11.88 \\
$\mathrm{~K}$ & 634.01 & 27.55 \\
$\mathrm{Mg}$ & 338.54 & 46.47 \\
$\mathrm{Mn}$ & 34.52 & 7.52 \\
$\mathrm{Mo}$ & $\mathrm{ND}$ & $\mathrm{ND}$ \\
$\mathrm{Na}$ & 25.3 & 4.6 \\
$\mathrm{Ni}$ & 0.04 & 0.01 \\
$\mathrm{P}$ & 103.08 & 15.75 \\
$\mathrm{~Pb}$ & 0.04 & 0.01 \\
$\mathrm{~S}$ & 101.13 & 15.22 \\
$\mathrm{Zn}$ & 5.1 & 0.21 \\
\hline
\end{tabular}

ND; not detected.

in nucleation reaction. Various biomolecules derived from plant biomass including amino acids, citric acid, flavonoids, functional groups, enzymes, peptides, sugars, tannic acid, and phenolics can be used as reducing agents as well as stabilizing agents [24]. Wood is one of the most abundant lignocellulosic biomasses on Earth and is usually produced as mixed species form. However, the biosynthesis of NPs using mixed barkless WCE has not been reported thus far. The compositional and elemental analyses of the woodchips were performed before the biosynthesis of the NPs. As seen in Table 1, the mixed woodchip powder mainly consists of cellulose, which can be converted into a reducing sugar, glucose. Klason lignin is the second largest component, followed by other sugar compounds originating from hemicellulosic part. In addition, the main mineral elements of the mixed woodchip powder are $\mathrm{K}, \mathrm{Ca}$, and $\mathrm{Mg}$ (Table 2), and trace amounts of heavy metals including $\mathrm{Cu}, \mathrm{Ni}$, and $\mathrm{Pb}$ were detected. Although it is difficult to obtain a high concentration of sugar solution from the woodchips by a simple hot water extraction, the result indicates that the woodchips contain high concentrations of various sugars with different chain lengths that can be used to synthesize NPs. In addition, the woodchips contain a negligible amount of harmful metals, which is a consideration for large-scale production processes. Therefore, it can be concluded that the sugar compounds prepared from the woodchips can be used to biosynthesize metal NPs.

\subsection{Effect of the Reaction Parameters on the Phytosynthesis of the Metal NPs}

3.2.1. Concentration of Precursor Metal Salts. One of the most important factors for the economic and efficient synthesis of NPs is determining the optimum concentration of the precursor metal salt. Therefore, the effect of the precursor salt concentration was evaluated for both metal NPs as indicated by time-dependent SPR absorbance measurements. In the case of AgNPs, the absorbance of the SPR band increased with the increase in the salt concentration in a time-dependent manner (Figure 1). The results indicate that phytosynthesis of AgNPs using WCE is dependent on the silver salt concentration and the duration of the reaction. In our experimental conditions, $\lambda_{\max }$ appeared between 428 and $439 \mathrm{~nm}$, and the absorbance at $\lambda_{\max }$ did not saturate during monitoring for $72 \mathrm{~h}$. Although the rate of AgNP synthesis depended on both the precursor salt and the reaction duration, no significant increase in the absorbance of the SPR band was observed (Figure 1(d)). Considering the cost of the silver salt, we concluded that $10 \mathrm{mM}$ of $\mathrm{AgNO}_{3}$ was sufficient for the AgNP biosynthesis, and this concentration was used for the subsequent experiments.

In contrast to the phytosynthesis of AgNPs, the formation of AuNPs did not correlate with the increasing precursor salt $\left(\mathrm{HAuCl}_{4}\right)$ concentration (Figure 2). The representative SPR band $(540 \mathrm{~nm})$ could be detected at the lowest tested concentration $(0.5 \mathrm{mM})$, and $\lambda_{\max }$ appeared between 539 and $542 \mathrm{~nm}$. However, there was no further increase in the absorbance of the SPR band after $24 \mathrm{~h}$, which indicated the saturation of the phytosynthesis. The gold ions rapidly reduced, aggregated, and precipitated at concentrations of the gold precursor salt above $1 \mathrm{mM}$. The precipitation was visible to the naked eye (data not shown). Therefore, the concentration of the gold salt was fixed at $0.5 \mathrm{mM}$ for subsequent experiments.

Although the optimum concentration of metal salts could be varied by adjusting other reaction parameters, the above results indicate that the formation of the metal NPs using WCE is dependent on the species of metals used.

3.2.2. Reaction $\mathrm{pH}$. The $\mathrm{pH}$ of the reaction mixture affects the rate of NP synthesis, morphology, and stability. In the case of the phytosynthesis of AgNPs using WCE, the reaction $\mathrm{pH}$ was the most important factor (Figure 3). Although the absorbance of the SPR band slightly increased with the increase in the $\mathrm{pH}$ up to $\mathrm{pH}$, the absorbance of SPR band significantly increased at $\mathrm{pH} 11$, and the reaction was almost completed after $24 \mathrm{~h}$ as shown by the timedependent absorbance values at $\lambda_{\max }$ (Figure $3(\mathrm{~d})$ ). Although the formation of the AgNPs increased in accordance with the reaction time, there was no drastic change at low $\mathrm{pH}(\sim \mathrm{pH} 9$, Figure $3(\mathrm{~d})$ ). To obtain detailed information on the effects of 


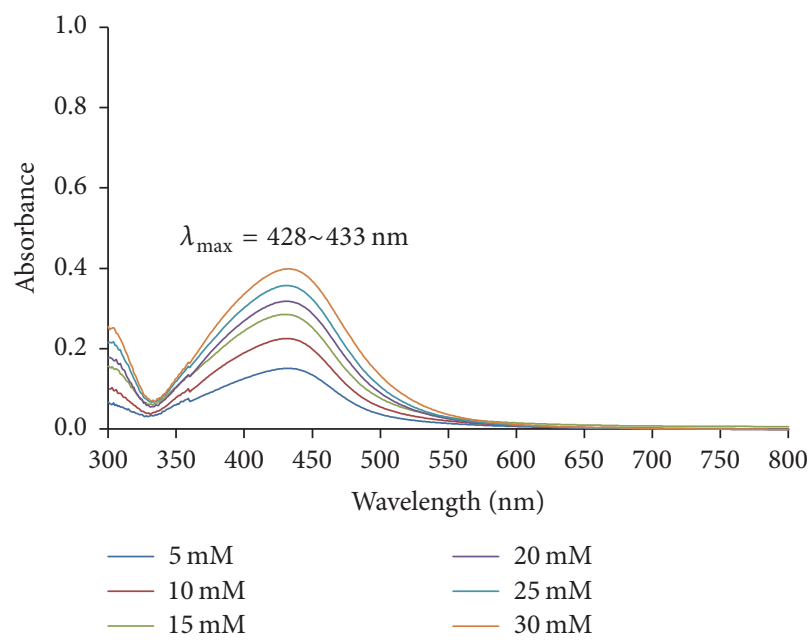

(a)

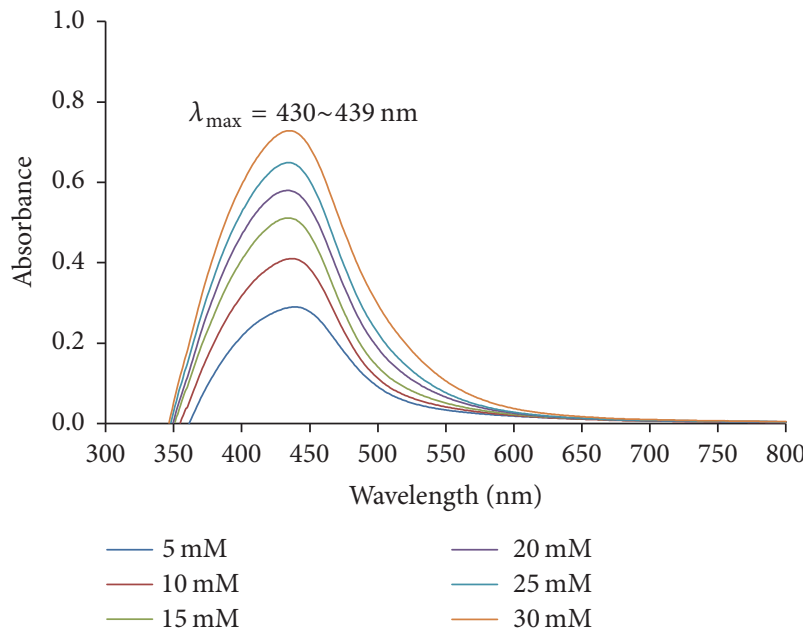

(c)

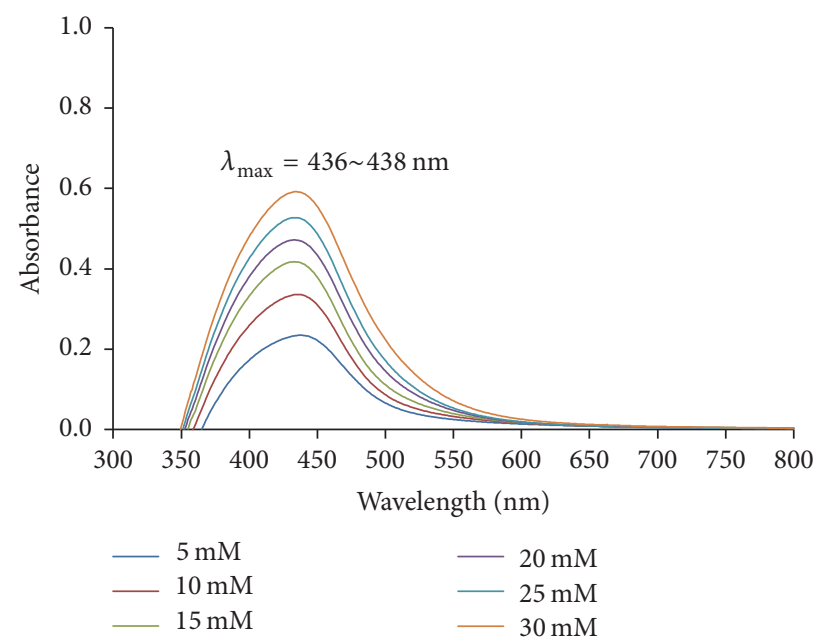

(b)

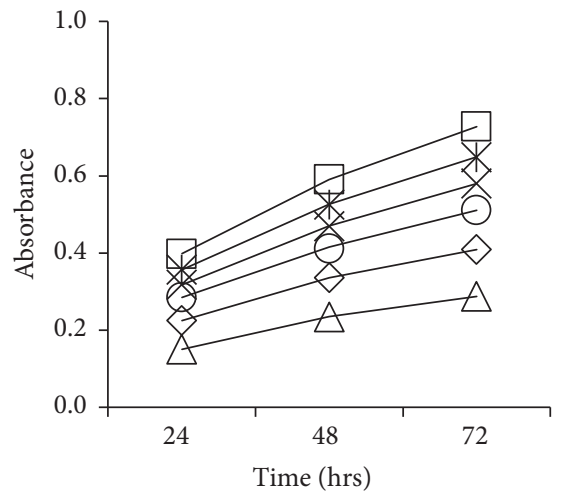

(d)

Figure 1: Effect of $\mathrm{AgNO}_{3}$ concentrations on the phytosynthesis of AgNPs after reaction for $24 \mathrm{~h}(\mathrm{a}), 48 \mathrm{~h}$ (b), and $72 \mathrm{~h}$ (c). Reaction curve demonstrating the evolution of the SPR band at $\lambda_{\max }$ as a function of time (d).

alkalinity on the phytosynthesis of AgNPs, alkaline $\mathrm{pH}$ values ranging from $\mathrm{pH} 9$ to $\mathrm{pH} 13$ were further analyzed. The effect of $\mathrm{pH}$ is clearly shown in Figure 4(a). The absorbance of SPR band significantly increased when the reaction $\mathrm{pH}$ was highly alkaline ( $\geqq \mathrm{pH} 12$ ), and the sharpest SPR band was observed at $\mathrm{pH}$ 13. In addition, the SPR band became shaper with the increase in the reaction $\mathrm{pH}$, which indicates a narrow size distribution for the AgNPs. In addition, the SPR band blueshifted with the increase in the $\mathrm{pH}$, shifting more dramatically above $\mathrm{pH} 11$ (Figure 4(b)). The time-course measurement of the SPR band formation at $\mathrm{pH} 13$ indicates that the phytosynthesis occurred immediately after the addition of silver salt, and the reaction was saturated after $4 \mathrm{~h}$ (Figures 4(c) and 4(d)). However, in the case of AuNPs, the AuNPs formed most rapidly at $\mathrm{pH} 5$ (Figure 5). A blue shift was also observed upon increasing the reaction $\mathrm{pH}$ (Figure 5(c) inset), but no further increase in the absorbance of SPR band was observed under alkaline conditions (Figure 5(d)). However, the absorbance of $\lambda_{\max }$ at neutral and acidic conditions gradually increased and decreased, respectively, over the duration of the reaction. These results demonstrate that the reaction $\mathrm{pH}$ plays a crucial role in the phytosynthesis of metal NPs using WCE.

Earlier reports indicated that the $\mathrm{pH}$ of a reaction mixture greatly influenced the biosynthesis of NPs as well as their stability. According to Andreescu et al. [25], an increase in the $\mathrm{pH}$ resulted in an increase in the absolute value of the negative zeta potential, which led to the formation of highly stable NPs. This phenomenon could be attributed to electrostatic repulsions at high $\mathrm{pH}$ or the high absolute value of the negative zeta potential [26]. In addition, the formation of large ellipsoidal AgNPs was observed at acidic $\mathrm{pH}$, while at higher $\mathrm{pH}$, well-dispersed small spherical NPs tended to form [27]. The authors speculated that the availability of a large number of functional groups enabled a higher number of silver ions to bind, thus forming a higher number of NPs with a smaller diameter. Although the optimum $\mathrm{pH}$ values for the AgNPs and AuNPs were different, these previous 


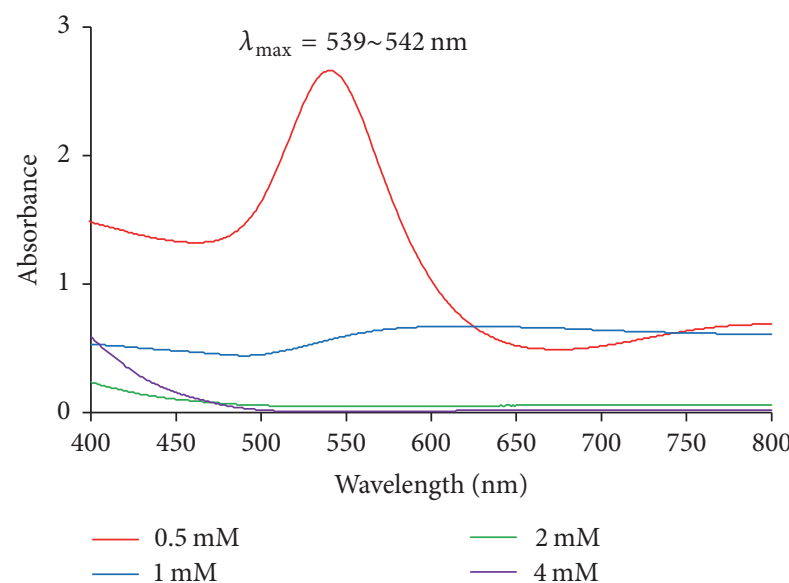

(a)

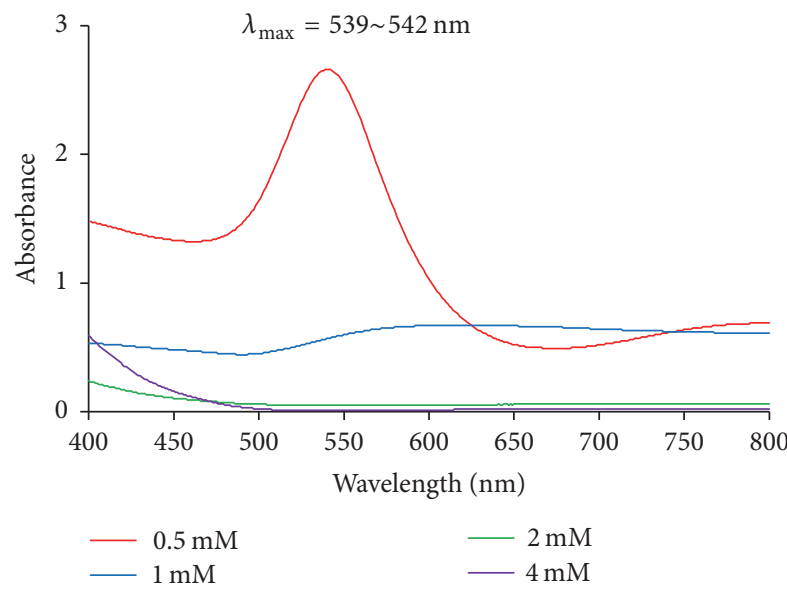

(c)

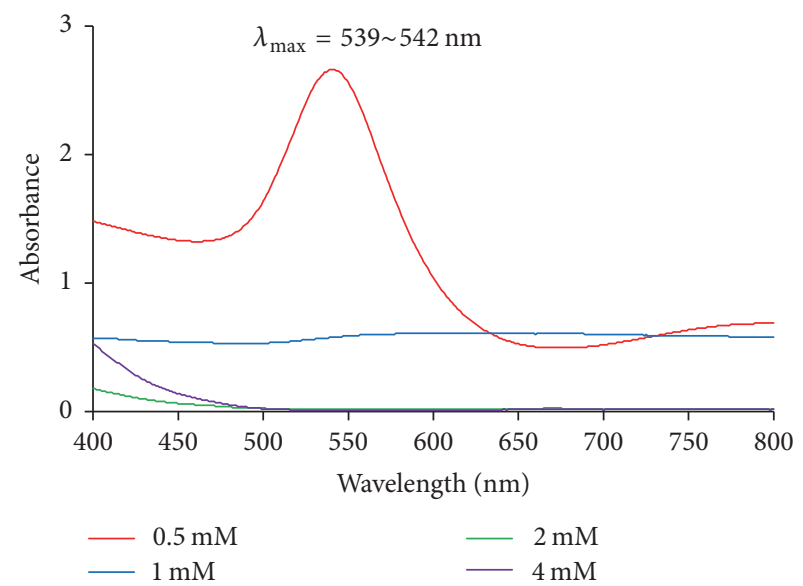

(b)

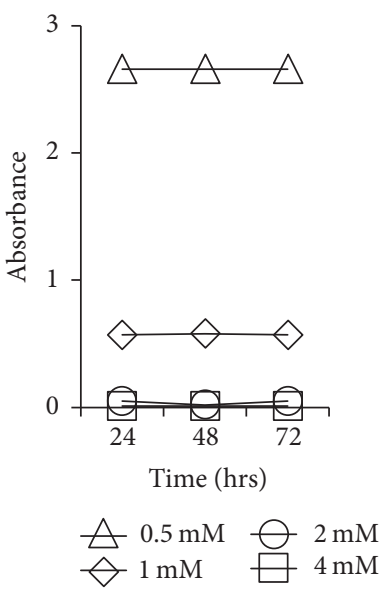

(d)

FIGURE 2: Effect of $\mathrm{HAuCl}_{4}$ concentrations on the phytosynthesis of AuNPs after reaction for $24 \mathrm{~h}$ (a), $48 \mathrm{~h}$ (b), and $72 \mathrm{~h}$ (c). Reaction curve demonstrating the evolution of the SPR band at $\lambda_{\max }$ as a function of time (d).

reports could explain the results from our experiments. In consideration of the rate of synthesis, $\mathrm{pH}$ values of 13 and 7 for the phytosynthesis of AgNPs and AuNPs, respectively, were used for subsequent experiments.

3.2.3. Concentration of the WCE. The amount of plant extract is an important factor affecting the size, shape, and synthesis rate of NPs [27-29]. However, different plant extracts may have different optimum concentrations for the phytosynthesis of NPs; therefore, the effect of the WCE concentration must be investigated for the efficient and costeffective phytosynthesis of the NPs. As shown in Figure 6, the effect of the WCE concentration on the phytosynthesis of AgNPs and AuNPs was clearly different. In the case of the AgNP phytosynthesis, the absorbance at $\lambda_{\max }$ increased with the WCE concentration (Figure 6(a)). Although a slight difference in the absorbance at $\lambda_{\max }$ was observed in the case of AuNP phytosynthesis, the results indicate that $1 \%$ WCE was sufficient for the reaction (Figure 6(b)). Similarly, Sun et al. [27] reported that the maximum efficiency was achieved in the phytosynthesis of AgNPs with 10\% tea extract, and the synthetic yield decreased when more than $25 \%$ tea extract was used. Thus, the results indicate that the optimum WCE concentration could vary with the metal species. Therefore, the WCE concentration is also a crucial factor that should be determined before production. Based on the above results, $5 \%$ and $1 \%$ WCE were used to phytosynthesize AgNPs and AuNPs, respectively, in subsequent experiments.

3.2.4. External Energy Input: Light and Heat. Any molecule that can reduce a metal ion to its zero valent state can be used to synthesize metal NPs. However, external energy may be required to stimulate the redox process by activating the molecules to act as a reducing agent in the reaction [30]. In our experiments, two kinds of external energy, light and heat, were used to investigate the effect of applying external energy to the phytosynthesis of AgNPs and AuNPs.

(1) Heat Energy. In general, the temperature of the reaction is crucial factor for the size [29], shape [31], and yield of NPs [32]. In the case of the phytosynthesis of AgNPs, they synthesized very rapidly (Figure 7). There was no timedependent correlation between the temperature and the phytosynthesis of AgNPs in our experimental conditions. 


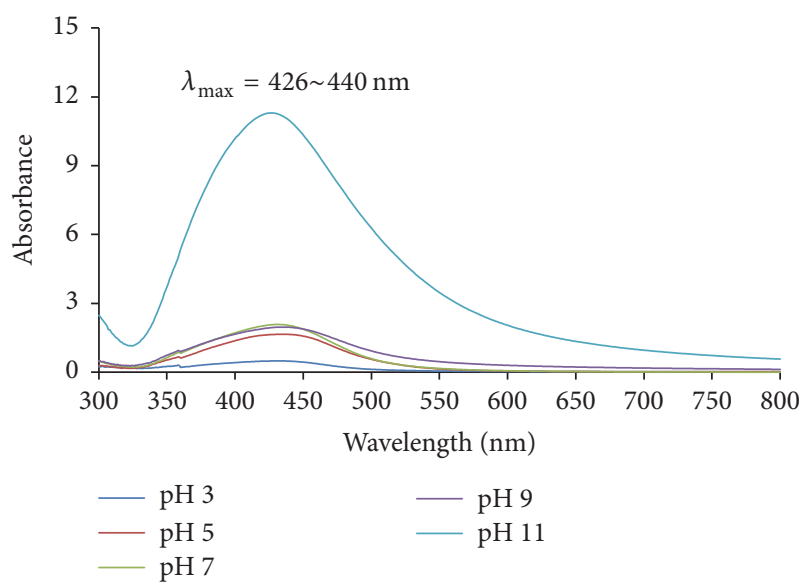

(a)

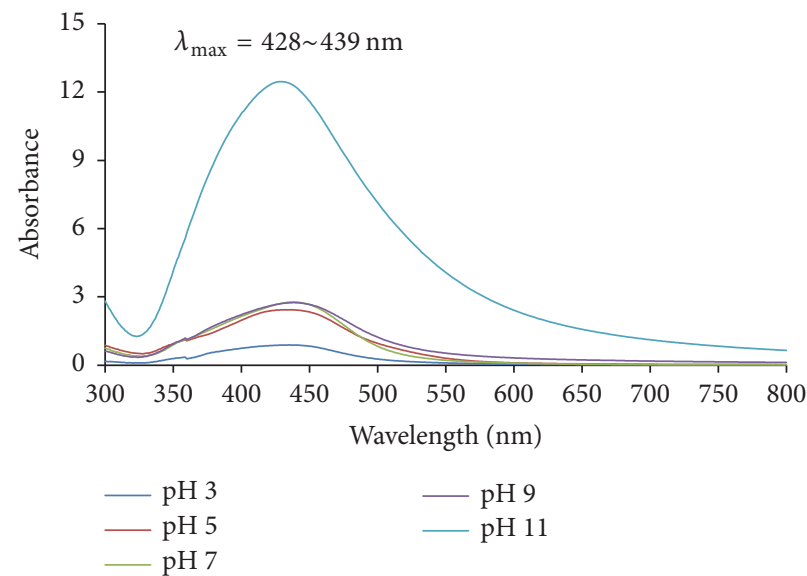

(c)

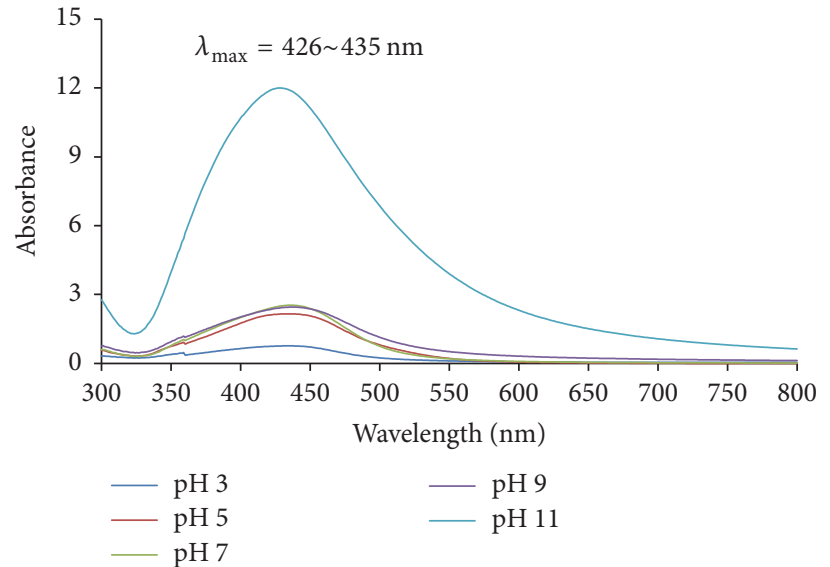

(b)

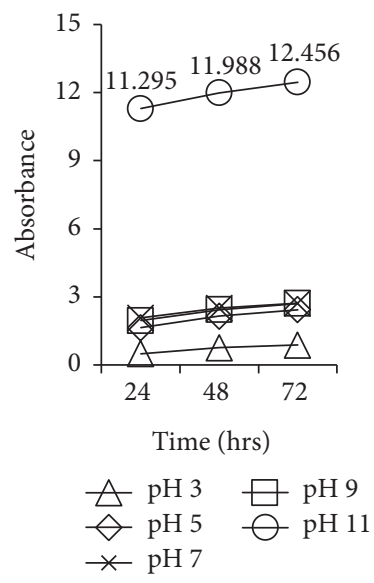

(d)

FiguRE 3: Effect of $\mathrm{pH}$ on the phytosynthesis of AgNPs after reaction for $24 \mathrm{hr}(\mathrm{a}), 48 \mathrm{hr}$ (b), and $72 \mathrm{hr}$ (c). Reaction curve demonstrating the evolution of the SPR band at $\lambda_{\max }$ as a function of time (d).

However, an increase in temperature resulted in a slightly sharper SPR band, which indicates the formation of smaller AgNPs with a narrow size distribution. When comparing the absorbance at $\lambda_{\max }$, the AgNP phytosynthesis above $40^{\circ} \mathrm{C}$ saturated after $30 \mathrm{~min}$ (Figure $7(\mathrm{f})$ ). However, phytosynthesis below $30^{\circ} \mathrm{C}$ was prolonged for $2 \mathrm{~h}$, and maximum synthesis occurred at $30^{\circ} \mathrm{C}$. Although the sharpest SPR band was observed at $60^{\circ} \mathrm{C}$, we selected $30^{\circ} \mathrm{C}$ as the optimum temperature for the AgNP phytosynthesis considering the cost effectiveness and the slight differences in the sharpness of the SPR band under various conditions. The result was somewhat different from those of earlier reports [29, 31, 32]; our results indicate that the optimum temperature could also vary with the plant material used. Therefore, the plant material should be carefully selected before optimizing the process to efficiently and cost-effectively phytosynthesize NPs at a large scale. Unlike the phytosynthesis of the AgNPs, the overall phytosynthesis of AuNPs showed temperature dependency excluding the reaction at $60^{\circ} \mathrm{C}$ (Figure 8). Excluding the reaction at $20^{\circ} \mathrm{C}$, the blue shift indicated that the NPs changed in size with the increase in temperature (Figure 8(e) inset).
Although the SPR band at $60^{\circ} \mathrm{C}$ was the sharpest among the experiments, the absorbance at $\lambda_{\max }$ was saturated and decreased after $1 \mathrm{~h}$ of the reaction, but a gradual timedependent increase in the absorbance at $\lambda_{\max }$ was observed under other conditions (Figure 8(f)). Although the SPR band of the AuNPs phytosynthesized at $40^{\circ} \mathrm{C}$ showed the broadest spectra, eventually, the optimum temperature for the maximum absorbance at $\lambda_{\max }$ was $40^{\circ} \mathrm{C}$. These results clearly demonstrate that the reaction temperature correlates with the initial yield of the NPs. However, the optimum temperature may differ for various metal ions and biomass or plant extracts used in the synthesis. In addition, a threshold temperature may determine the final conversion yield when the size range of the NPs is not a top priority.

(2) Light Energy. Light energy may be a suitable stimulus to produce the chemical changes involved in NP formation. Light is well known to induce various redox processes and to produce active species that can be used to reduce metal ions [30]. Together with the heat energy input, the effectiveness of light energy applied to the phytosynthesis of metal NPs was investigated. 


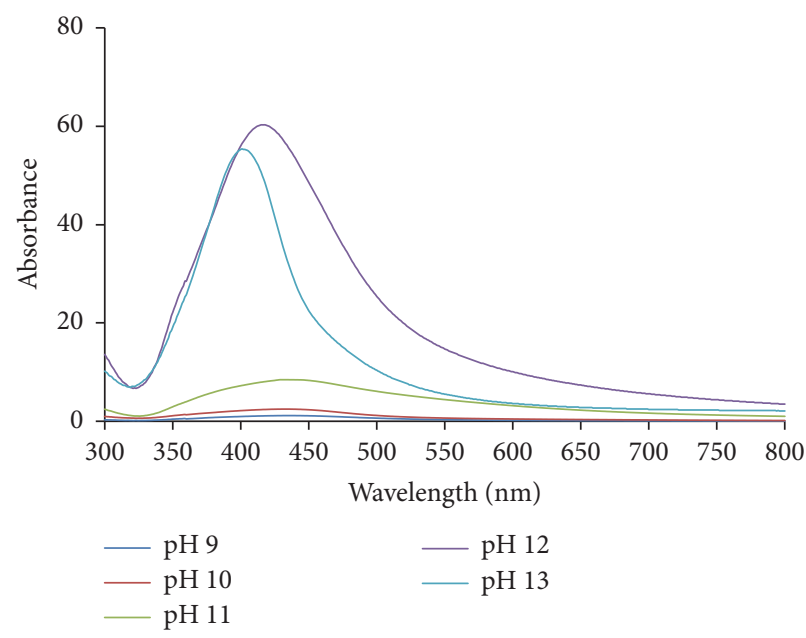

(a)

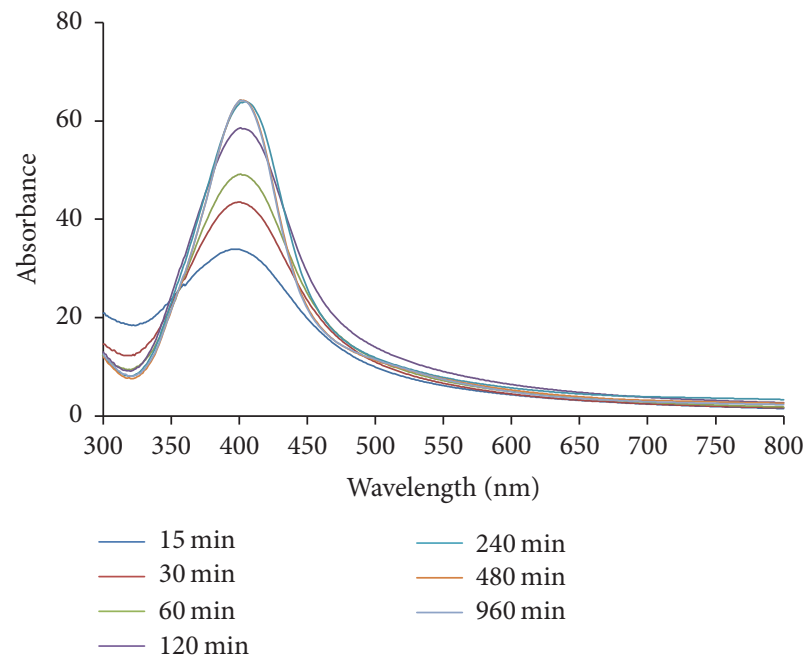

(c)

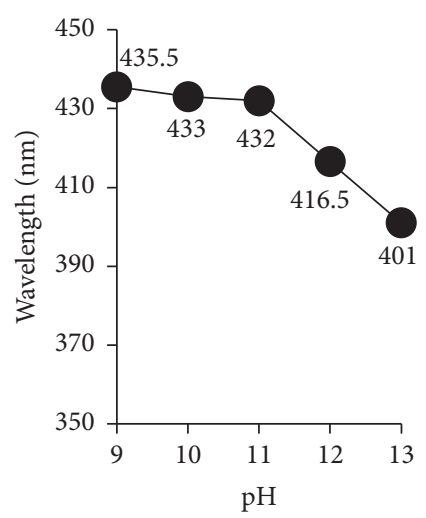

(b)

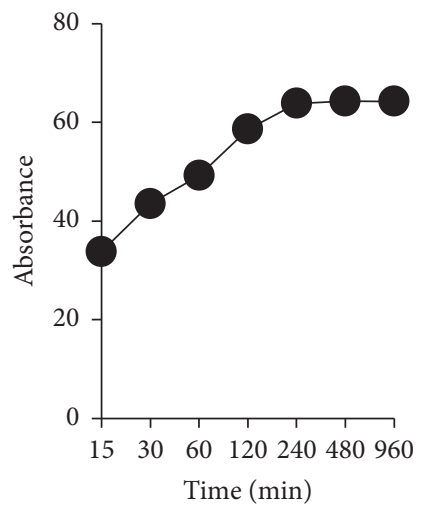

(d)

FIgURE 4: Effect of alkaline $\mathrm{pH}$ on the phytosynthesis of AgNP. UV-Vis spectrum after reaction for $24 \mathrm{~h}$ at various $\mathrm{pH}$ values (a), blue shift of the SPR band depicted by average $\lambda_{\max }$ values at various $\mathrm{pH}$ (b), time-course measurement of UV-Vis spectrum at $\mathrm{pH} 13$ (c), and reaction curve at $\mathrm{pH} 13$ depicted by average $\lambda_{\max }$ as a function of time (d).

In the case of the visible-light-assisted phytosynthesis of AgNPs using WCE, the initial reaction occurred very rapidly, and the results demonstrated that light energy efficiently enhanced the yield of AgNPs (Figure 9). To achieve the maximum SPR band height, $100 \mu \mathrm{mol} / \mathrm{m}^{-2} / \mathrm{s}$ of light irradiance was sufficient (Figure 9(d)). In addition, light irradiance was more effective than heat energy when comparing the absorbance at $\lambda_{\max }$ after $1 \mathrm{~h}$ of reaction (Figures 7 (b) and 9(c)). In the case of the AuNPs, the optimum irradiance strength could be defined as above $100 \mu \mathrm{mol} / \mathrm{m}^{-2} / \mathrm{s}$ (Figure 10). The absorbance spectrum blue-shifted at high light energy conditions $\left(\geqq 100 \mu \mathrm{mol} / \mathrm{m}^{-2} / \mathrm{s}\right)$, as shown in Figure $10(\mathrm{e})$. Although the height of the SPR band gradually increased in a time-dependent manner, the height of the SPR band did not increase more with the light energy input than with heat (Figure 8). This result might be due to the low concentration of added precursor gold salts and may indicate that the gold ions were completely reduced in our experimental conditions.

3.2.5. Conversion Yield of AgNPs and AuNPs. The conversion yield from silver and gold metal ions to their NP forms using WCE was determined after evaluating the individual reaction parameters. The atomic concentration of the NP solution in Section 3.2.4(2) demonstrates that more than $90 \%$ of the precursor salts were converted into NPs (Figure 11). Conversion yield is an important criterion for commercial-scale production because it is directly linked to the production cost. Therefore, the results clearly indicate that WCE can be effectively used for large-scale metal NP production when the reaction parameters are properly adjusted.

\subsection{Characterization of the As-Synthesized NPs}

3.3.1. Silver Nanoparticles. The representative TEM image of the purified AgNPs in Figure 12(a) shows that the particles 


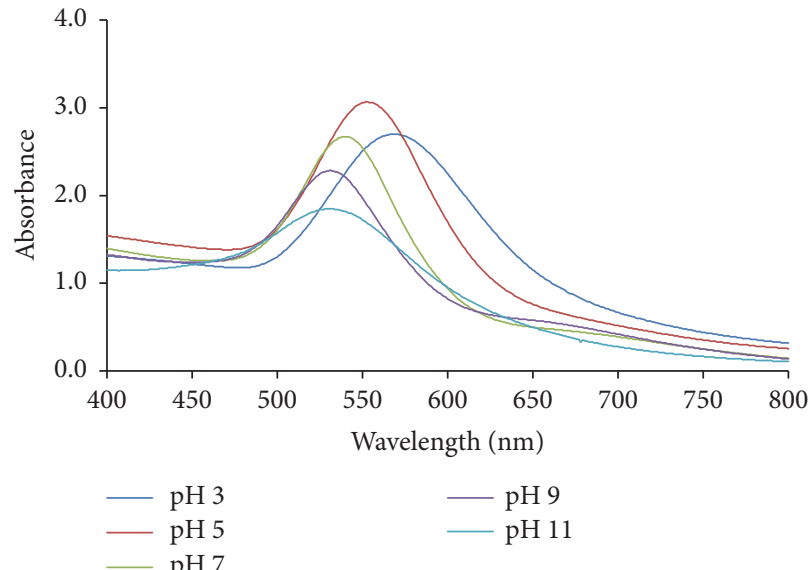

(a)

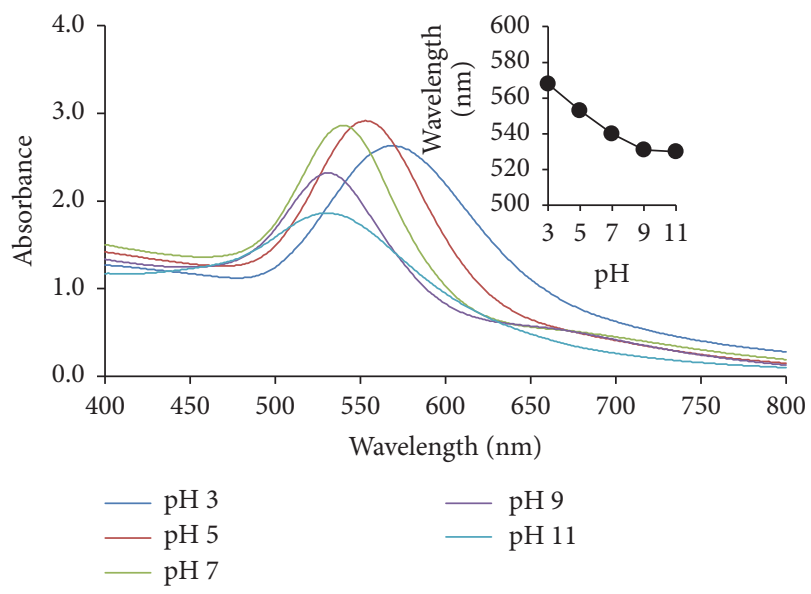

(c)

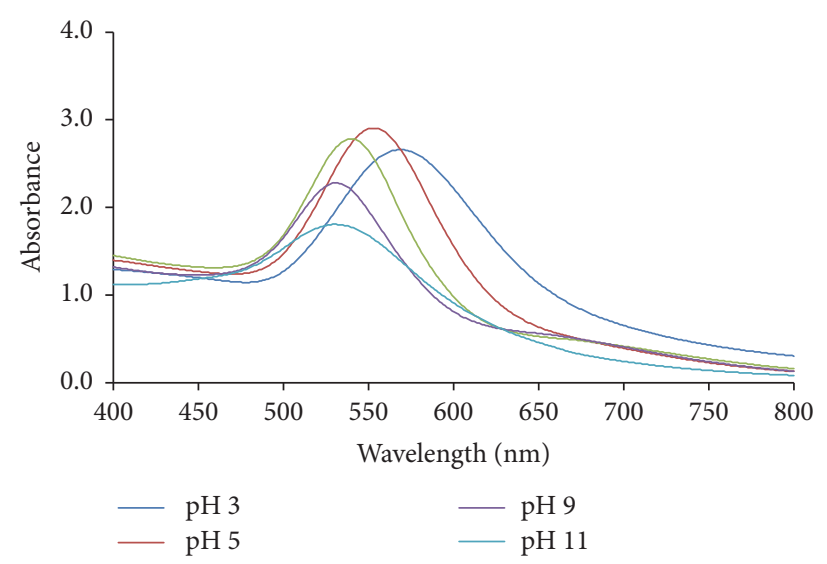

(b)

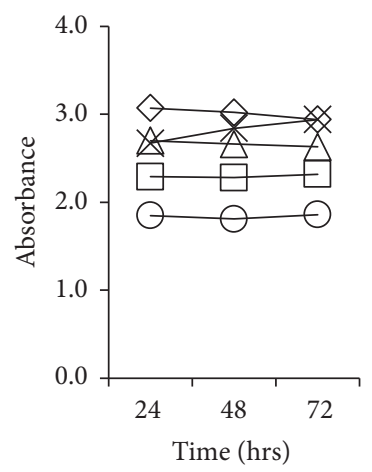

$\diamond \mathrm{pH} 5$
$\times \mathrm{pH} 7$

(d)

FiguRE 5: Effect of reaction $\mathrm{pH}$ on the phytosynthesis of AuNPs after reaction for $24 \mathrm{~h}$ (a), $48 \mathrm{~h}$ (b), and $72 \mathrm{~h}$ (c). Effect of pH values on the blue shift of the SPR band depicted by average $\lambda_{\max }$ values (inset (c)). Reaction curve demonstrating the evolution of the SPR band at $\lambda_{\max }$ as a function of time (d).

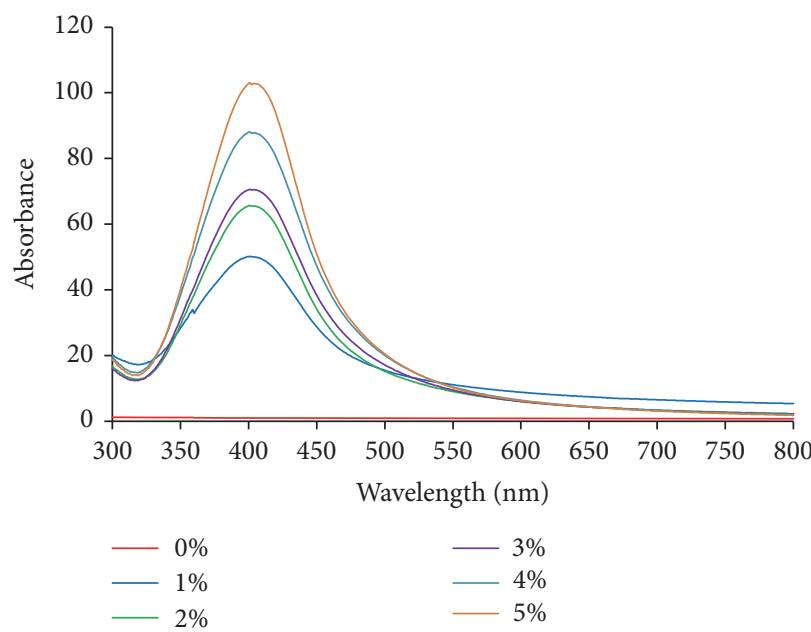

(a)

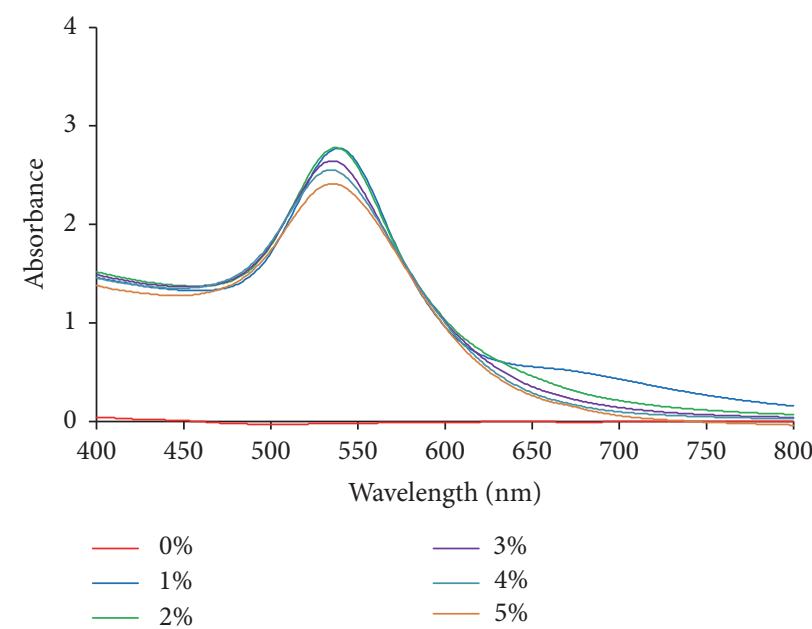

(b)

Figure 6: Effect of WCE concentration on the phytosynthesis of AgNP (a) and AuNP (b) after $24 \mathrm{~h}$. 

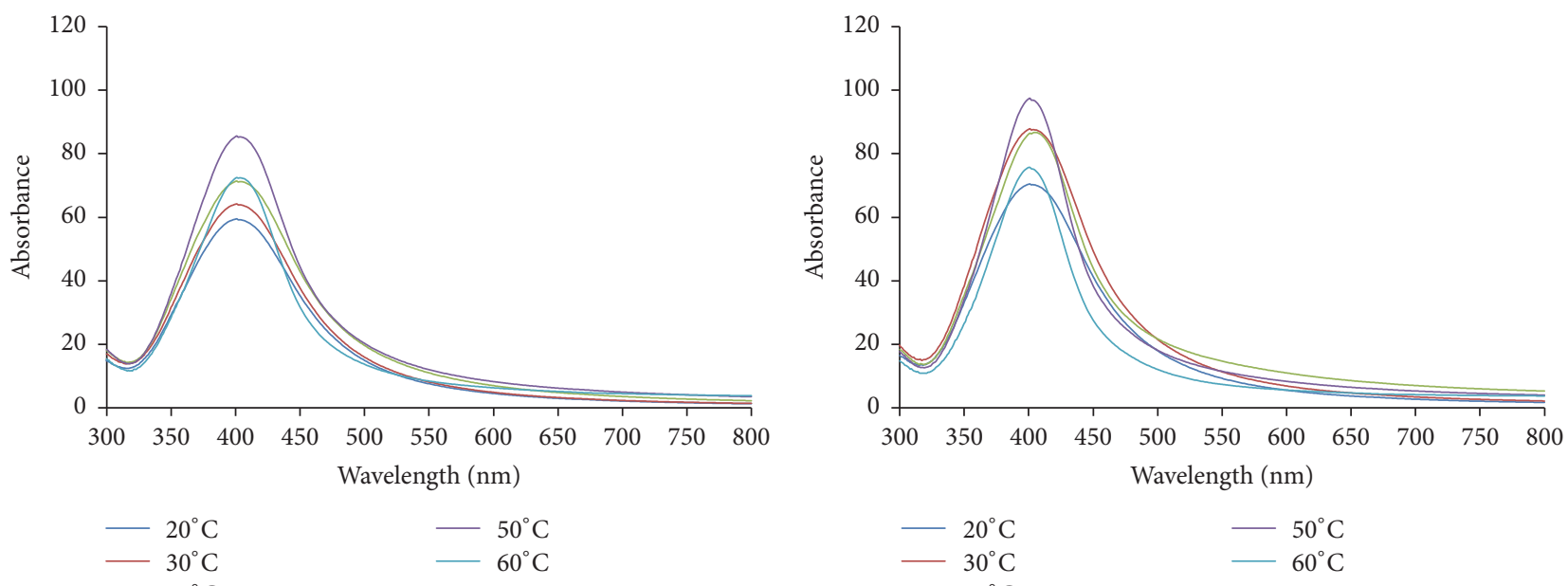

(a)
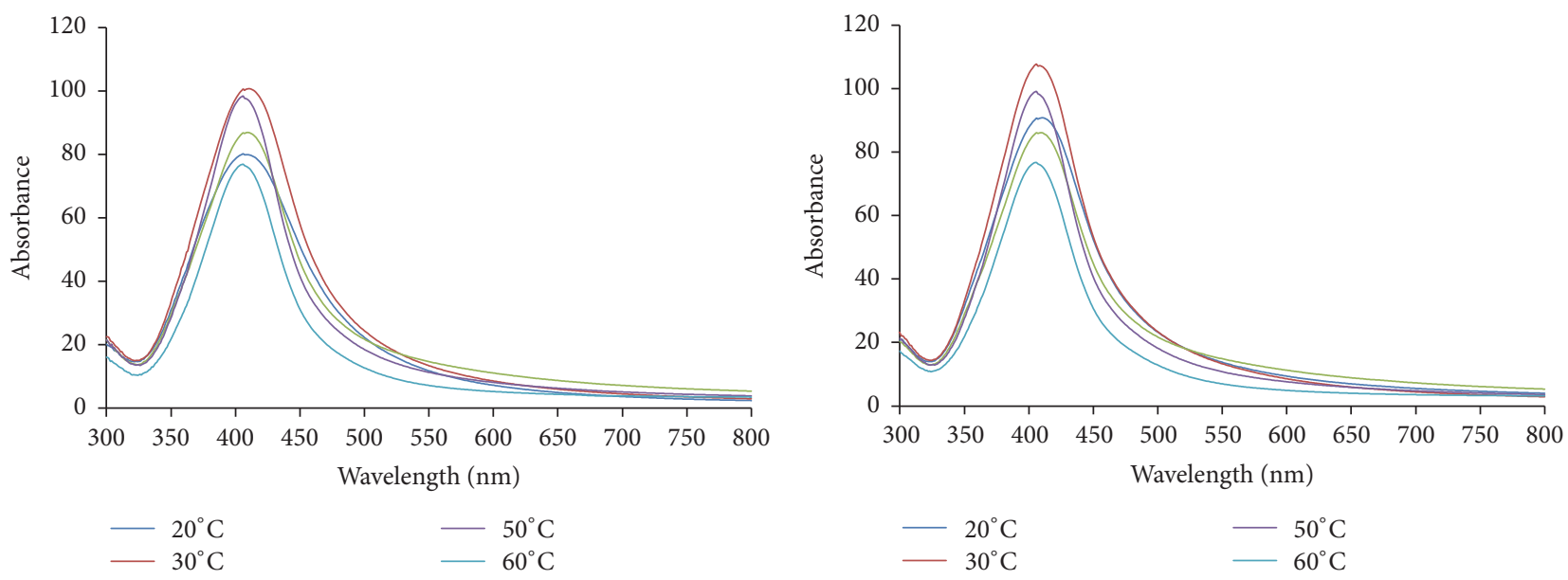

(c)

(d)
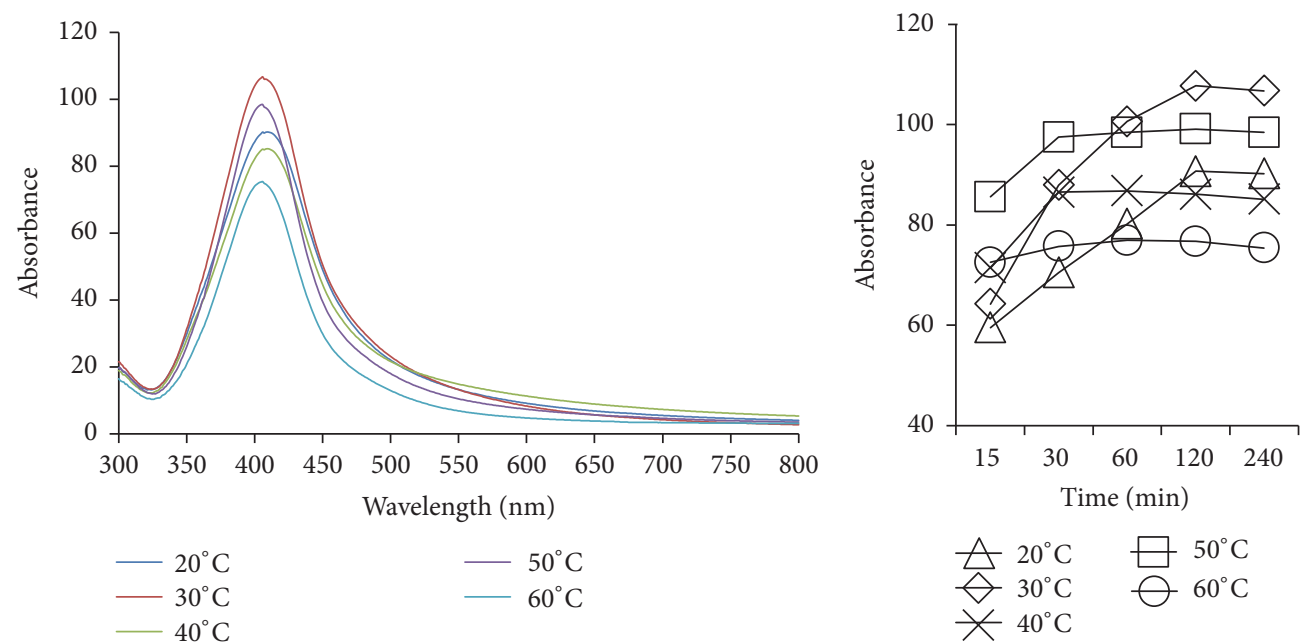

(e)

$\triangle 20^{\circ} \mathrm{C} \quad \square 50^{\circ} \mathrm{C}$
$\forall 30^{\circ} \mathrm{C} \quad \bigcirc 60^{\circ} \mathrm{C}$
$\times 40^{\circ} \mathrm{C}$

(f)

Figure 7: Effect of temperature on the phytosynthesis of AgNPs after reaction for $15 \mathrm{~min}$ (a), $30 \mathrm{~min}$ (b), $60 \mathrm{~min}$ (c), $120 \mathrm{~min}$ (d), and $240 \mathrm{~min}$ (e). Reaction curve demonstrating the evolution of the SPR band at $\lambda_{\max }$ as a function of time at different reaction temperatures (f). 

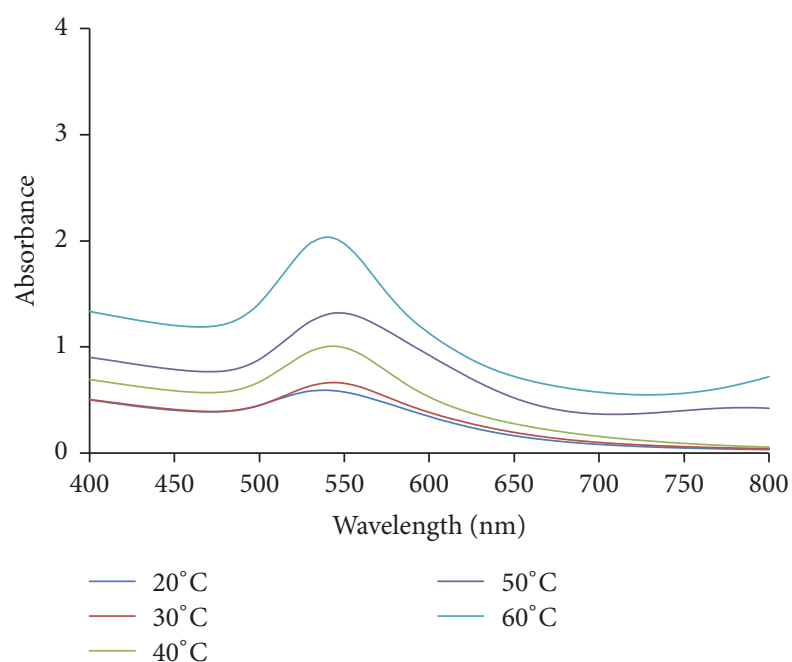

(a)

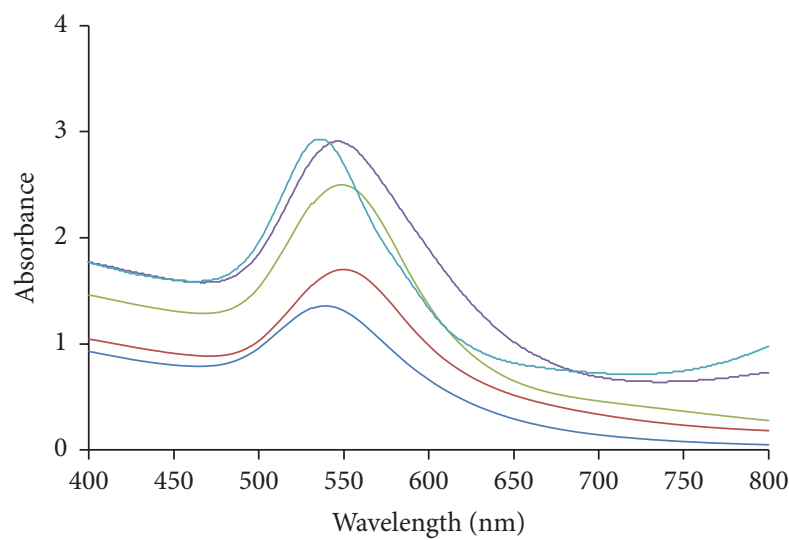

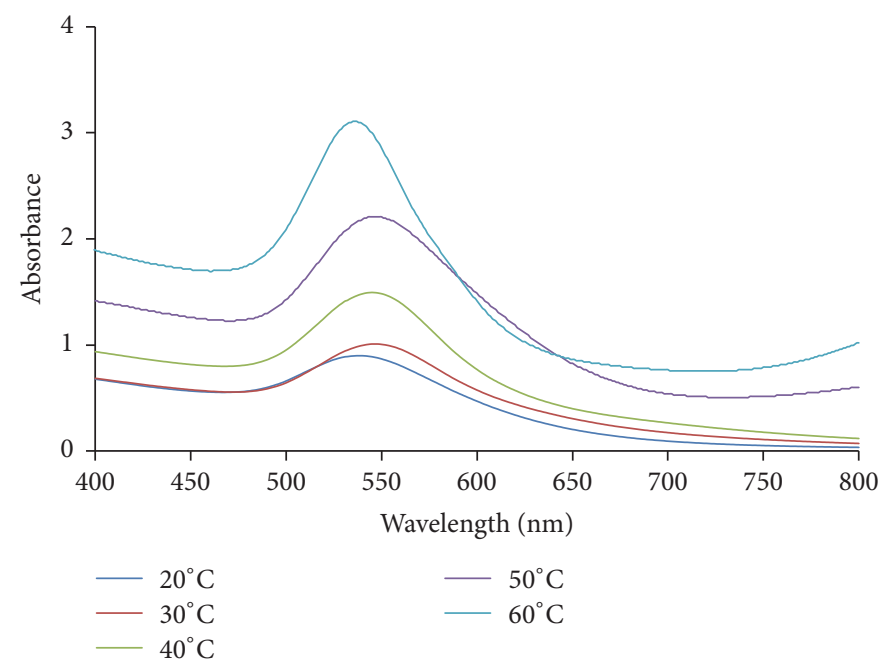

(b)

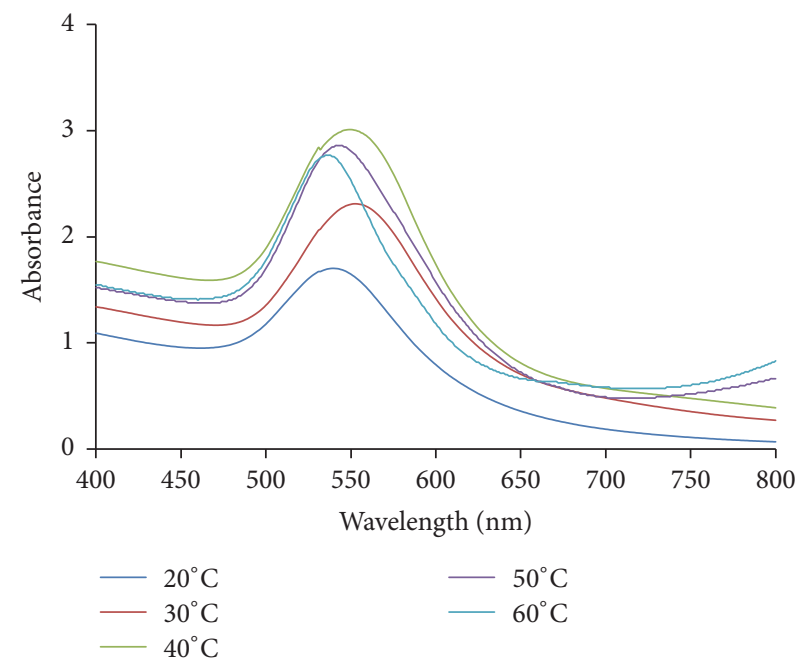

(d)

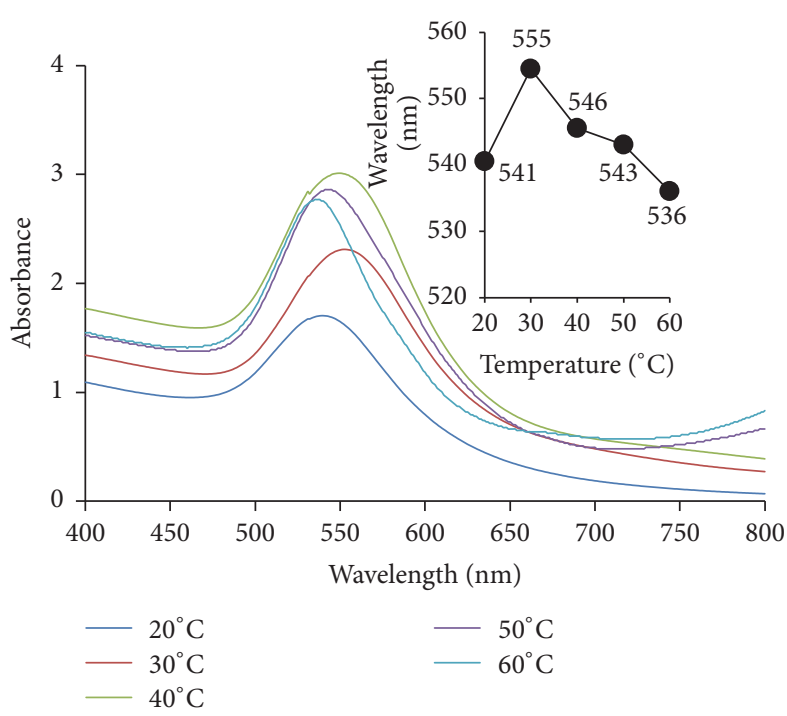

(e)

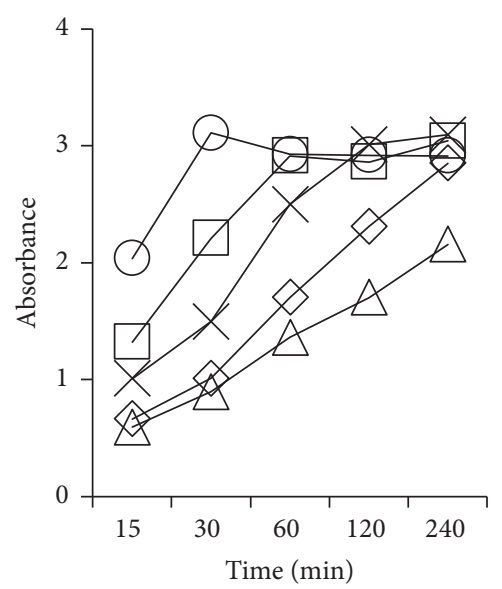

$\triangle 20^{\circ} \mathrm{C} \quad \square 50^{\circ} \mathrm{C}$ $\diamond 30^{\circ} \mathrm{C} \oslash 60^{\circ} \mathrm{C}$ $\Varangle 40^{\circ} \mathrm{C}$

(f)

Figure 8: Effect of temperature on the phytosynthesis of AuNPs after reaction for $15 \mathrm{~min}$ (a), $30 \mathrm{~min}$ (b), $60 \mathrm{~min}$ (c), $120 \mathrm{~min}$ (d), and $240 \mathrm{~min}$ (e). Effect of temperature on the blue shift of the SPR band depicted by average $\lambda_{\max }$ values (inset (e)). Reaction curve demonstrating the evolution of the SPR band at $\lambda_{\max }$ as a function of time at different reaction temperatures (f). 


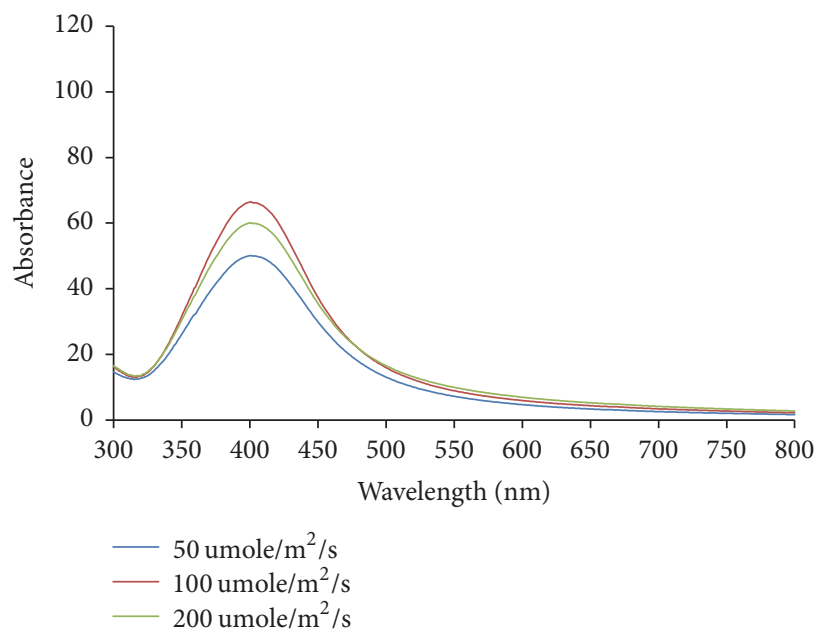

(a)

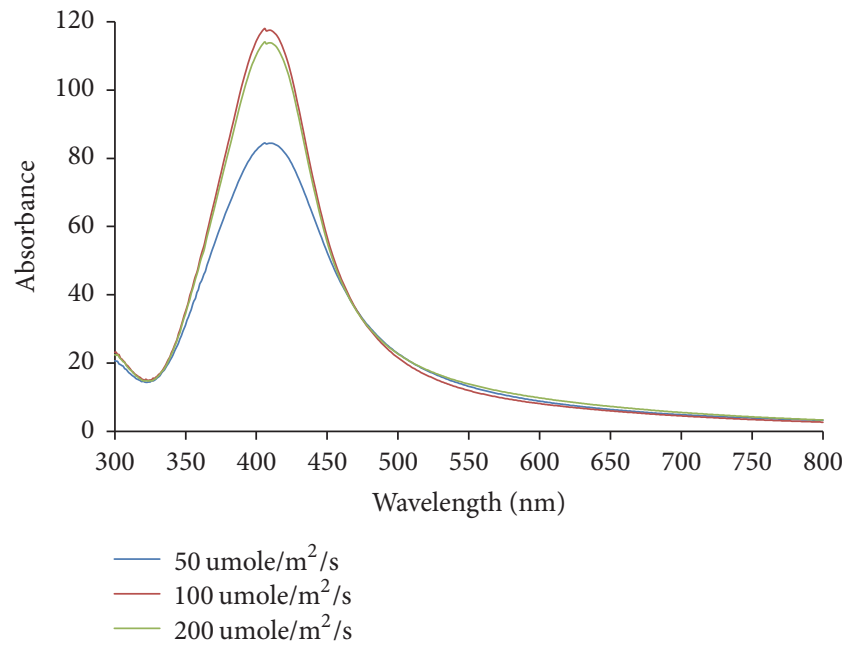

(c)

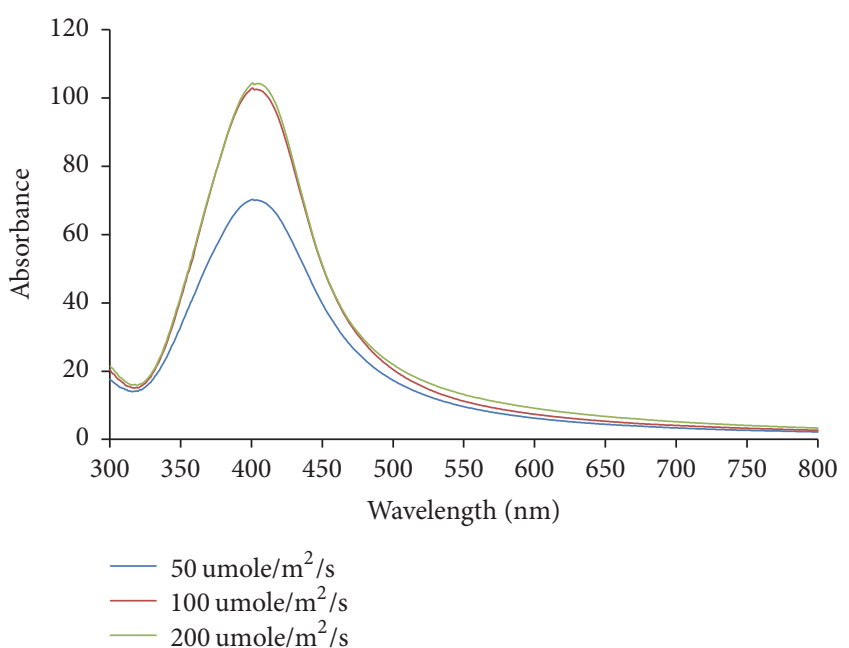

(b)

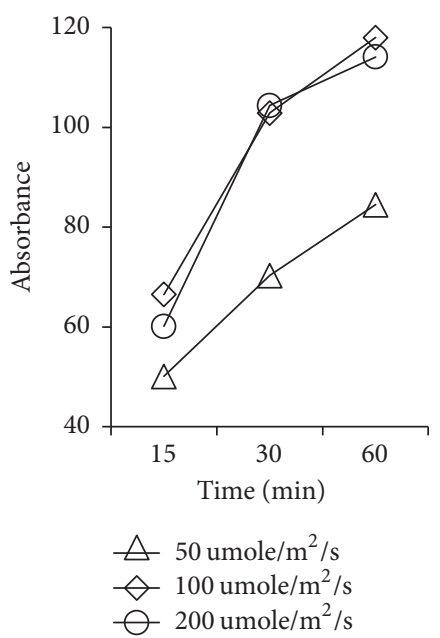

(d)

FIGURE 9: Effect of LED light irradiance on the phytosynthesis of AgNPs after reaction for 15 min (a), 30 min (b), and 60 min (c). Reaction curve demonstrating the evolution of the SPR band at $\lambda_{\max }$ as a function of time at different LED light intensities (d).

are monodispersed and mostly spherical. The size of the AgNPs ranged from as low as $6 \mathrm{~nm}$ to as high as $32 \mathrm{~nm}$ and the average size was $13 \mathrm{~nm}$ (Figure 12(b)). The EDX spectrum of the AgNPs indicates the presence of silver atoms (Figure 12(c)). Other atoms including carbon, oxygen, phosphor, copper, and sulfur might come from the WCE and the carbon-coated copper grid. Lattice fringes of 4.070, 4.068, 4.073 , and $4.079 \AA$ corresponding to the lattice distance of face-centered cubic (fcc) silver were observed (Figure 13(a)). The Scherrer ring pattern characteristic of fcc silver was also observed (Figure 13(b)), indicating that the AgNPs were nanocrystalline in nature. The crystallinity was further analyzed by XRD (Figure 13(c)), and the Bragg reflections for (111), (200), (220), (311), and (222) planes agree well with those reported for fcc silver. The most intense peak at $2 \theta$ $=69.2^{\circ}$ corresponds to Si from the wafer, and some intense diffraction peaks might come from unknown compounds caused by a reaction between $\mathrm{AgNO}_{3}$ and the remaining
WCE components such as nanosized woodchip particles or partially thermally digested cellulosic and hemicellulosic biomass. Together with the diffraction data from the HRTEM analysis, the results demonstrate the successful phytosynthesis of the AgNPs using WCE.

3.3.2. Gold Nanoparticles. Microscopic (TEM) results indicate that the phytosynthesized AuNPs are well dispersed and irregular in shape (Figure 14). The size of the AuNPs ranged from $28 \mathrm{~nm}$ to $48 \mathrm{~nm}$, and the average size was $39 \mathrm{~nm}$ (Figure 14(b)). The EDX spectrum of the AuNPs confirms the presence of gold atoms (Figure 14(c)). Other atoms including carbon, oxygen, and silicon were also detected, which might originate from the WCE. Similar to the AgNPs, lattice fringes of $4.070,4.068,4.073$, and $4.079 \AA$ were observed, corresponding to the lattice distance of fcc gold (Figure 15(a)). The SAED pattern of the AuNPs shows ring patterns with intense spots assigned to (111), (200), (220), and (311) planes of 


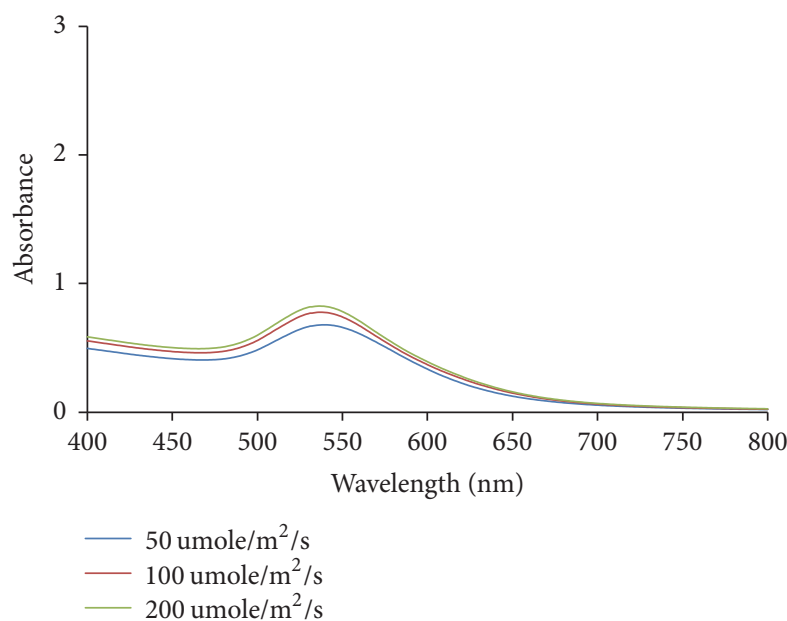

(a)

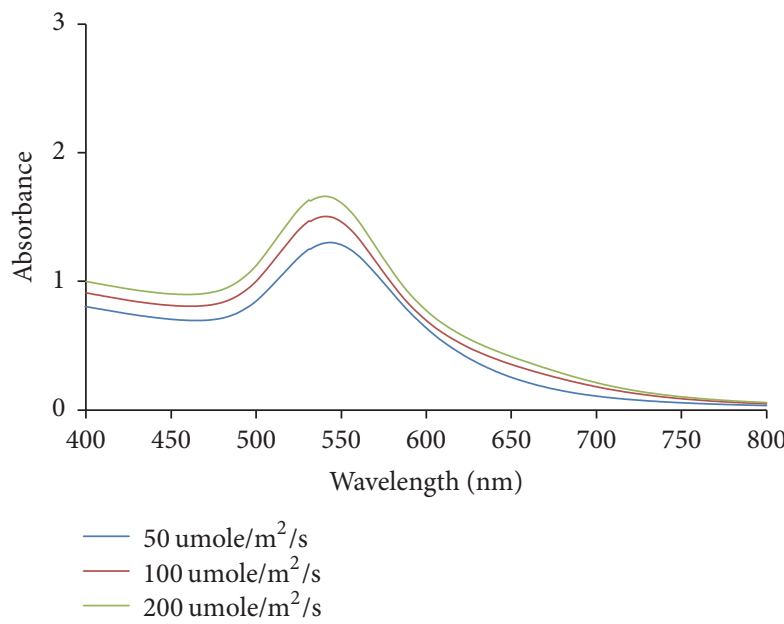

(c)

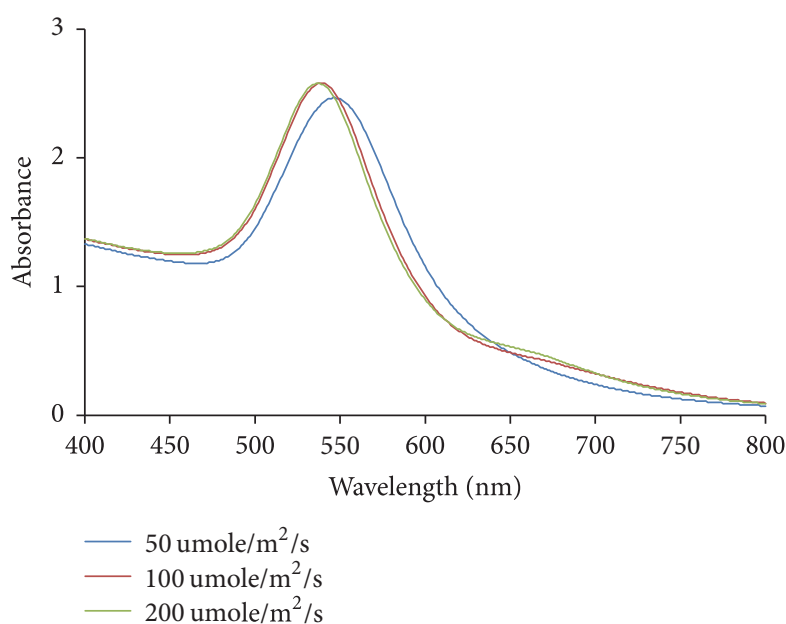

(e)

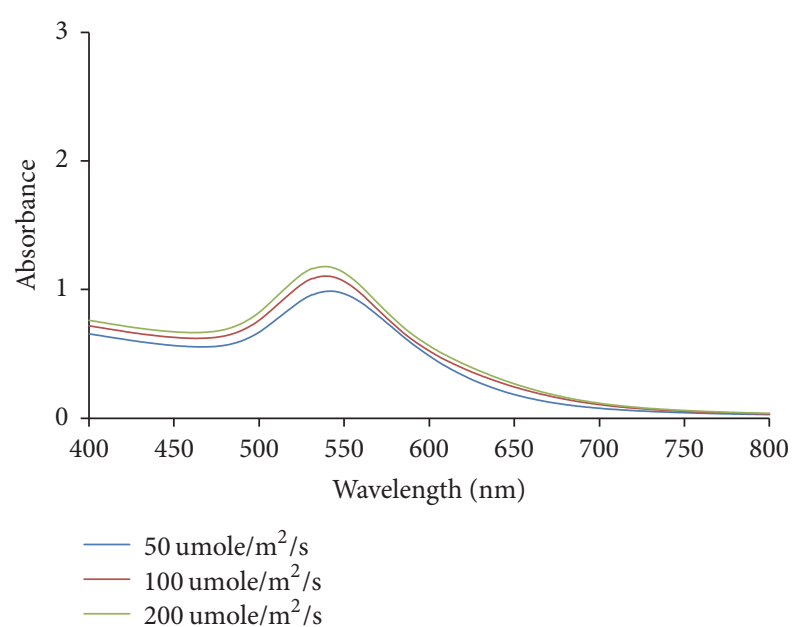

(b)

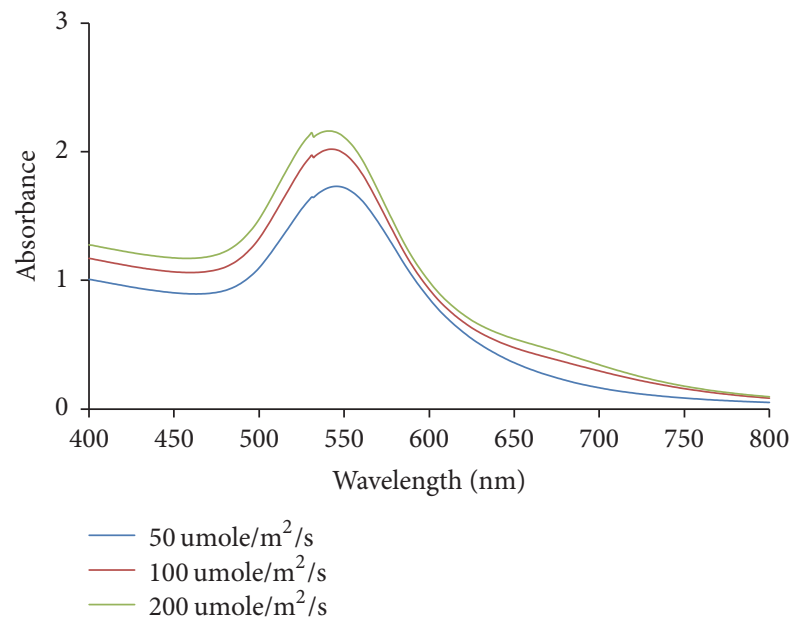

(d)

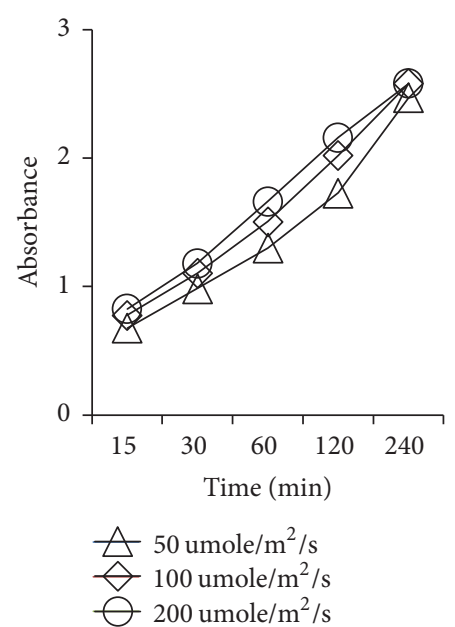

(f)

FIGURE 10: Effect of LED light irradiance on the phytogenic synthesis of AuNP after reaction for $15 \mathrm{~min}$ (a), $30 \mathrm{~min}$ (b), $60 \mathrm{~min}$ (c), $120 \mathrm{~min}$ (d), and $240 \mathrm{~min}$ (e). Reaction curve demonstrating the evolution of the SPR band at $\lambda_{\max }$ as a function of time at different LED light intensities (f). 


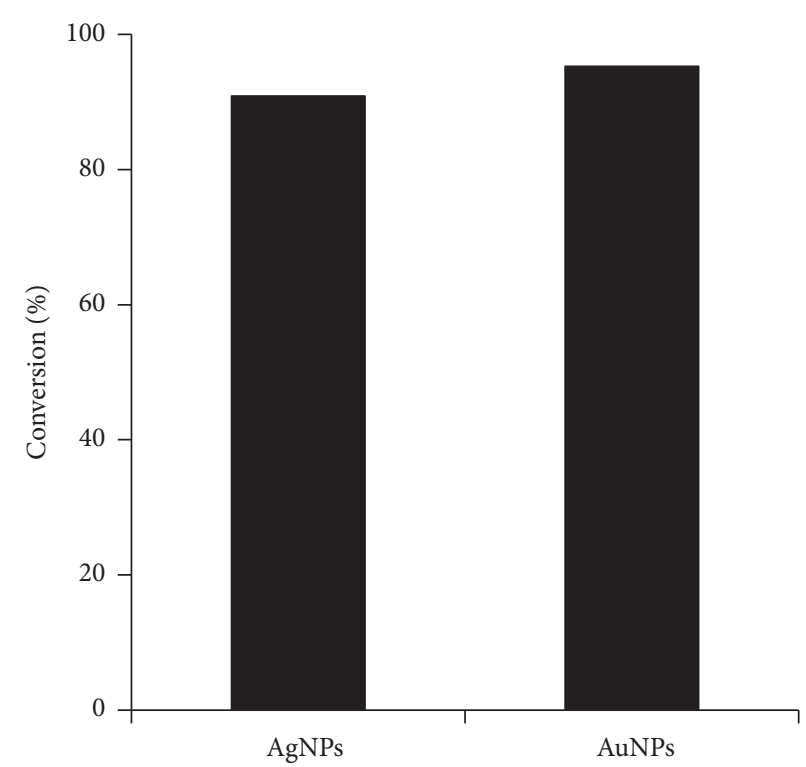

Figure 11: Yield of AgNPs and AuNPs synthesized by WCE.
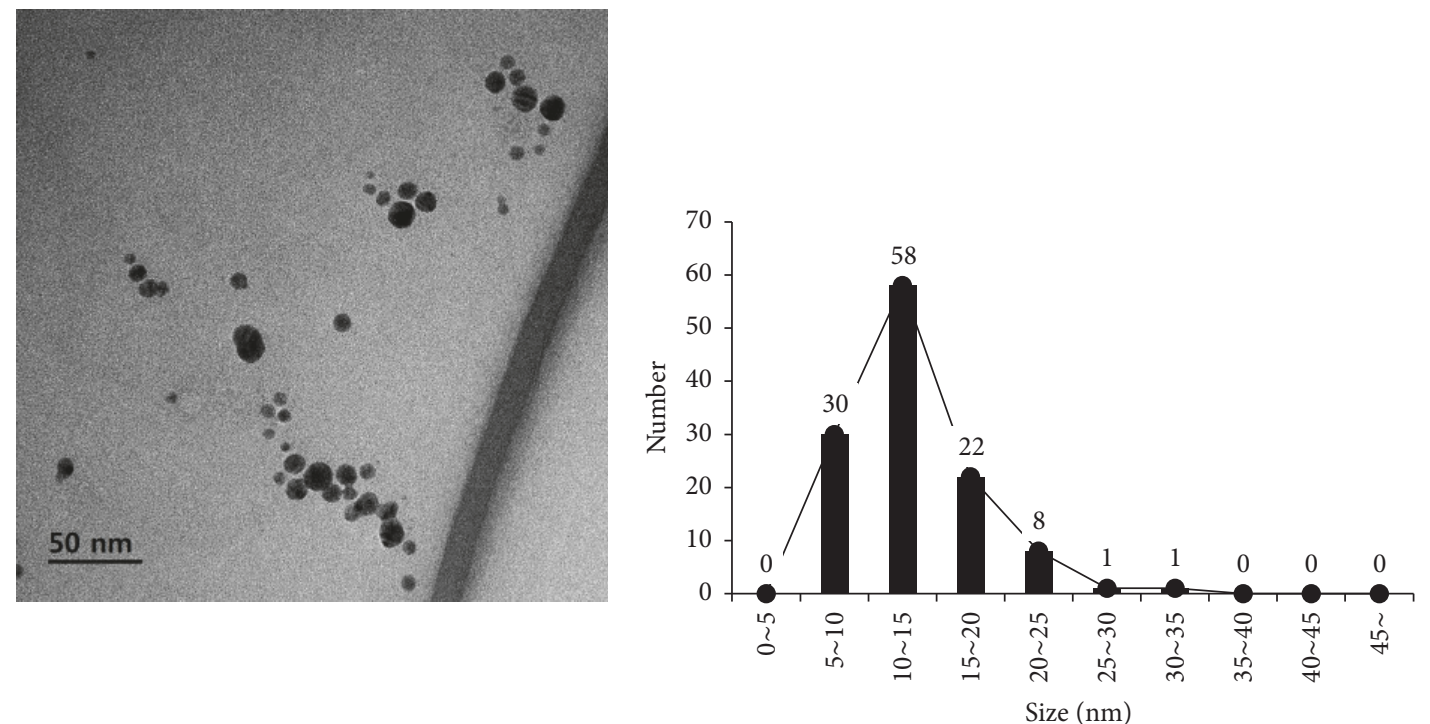

(a)

(b)

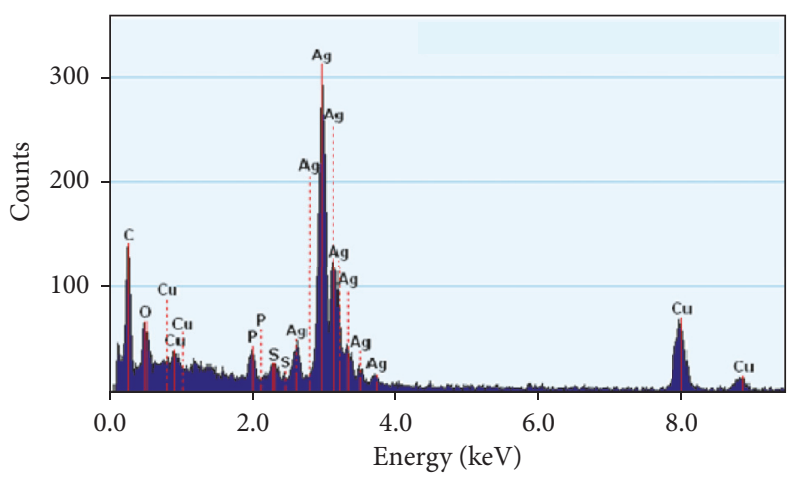

- 16.37.41 acquire HAADF point 1

(c)

FIgURE 12: A representative TEM image of the AgNPs (a), a particle size distribution histogram of the AgNPs determined from TEM images (b), and EDX results of a single AgNP (c). 


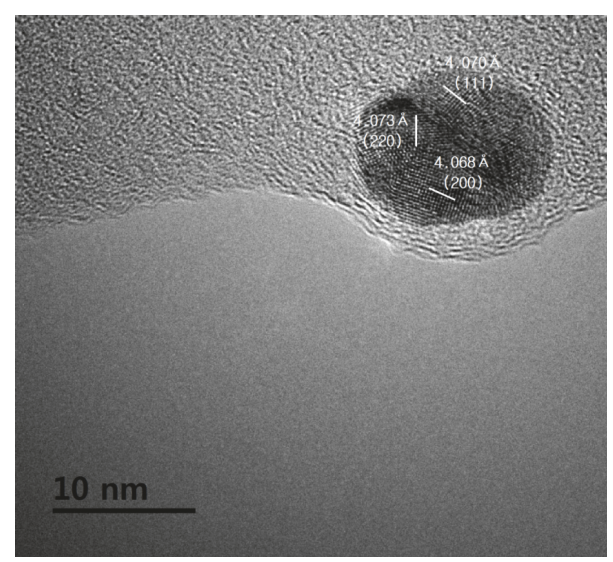

(a)

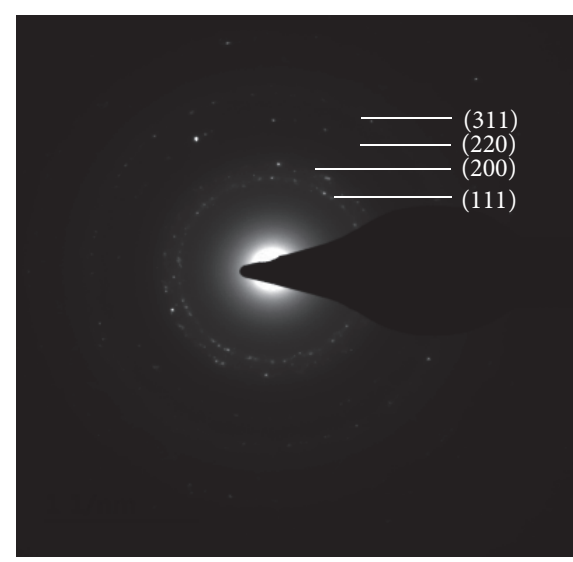

(b)

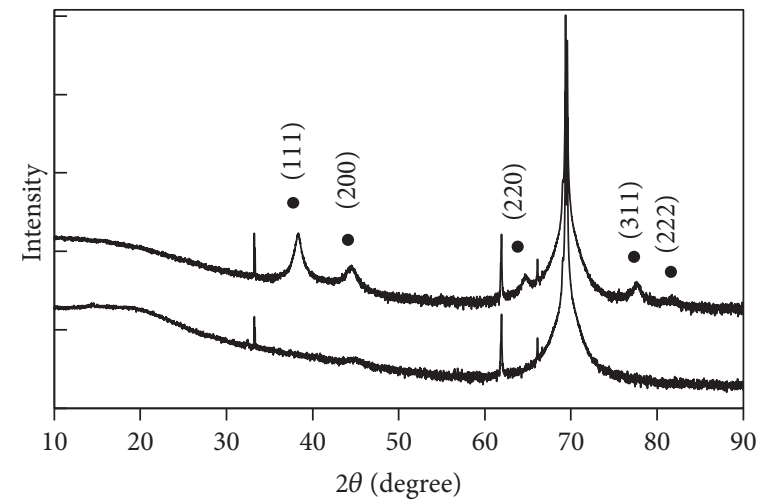

(c)

FIGURE 13: HR-TEM image of a single polycrystalline AgNP (a), SAED pattern with the diffraction rings indexed with reference to fcc silver (b), and XRD patterns of WCE (lower line) alone and the as-synthesized AgNPs (upper line) (c).

typical gold fcc crystals (Figure 15(b)), thus indicating that the AuNPs are nanocrystalline in nature. The crystallinity of the purified AuNPs was further confirmed by XRD with $\mathrm{Cu} \mathrm{K} \alpha$ radiation (Figure 15(c)). The diffraction pattern confirmed the formation of crystalline AuNPs. Similar to the XRD results of the AgNPs, the AuNPs exhibited four dominant XRD diffraction peaks, which could be indexed to (111), (200), (220), and (311) planes of polycrystalline fcc gold. In addition, some other intense diffraction peaks were detected, including those for Si. Altogether, the XRD results were consistent with the HR-TEM images and the SAED results, indicating the polycrystallinity of the AuNPs.

3.3.3. Efficacy of the Antibacterial Activity. Two Grampositive and two Gram-negative bacterial strains were used to evaluate the antibacterial efficacy of the phytosynthesized NPs. The results showed that the AgNPs possess antibacterial activity against all the tested strains, which demonstrates their potential as bactericidal agents in clinical and biomedical applications (Figure 16). Among the strains, B. subtilis and $E$. coli showed the highest and lowest susceptibility, respectively. The variation in the zone of inhibition observed with different bacterial strains may be due to the difference in bacterial susceptibility against the AgNPs. On the contrary, the phytosynthesized AuNPs showed no significant antibacterial activity at concentrations up to $400 \mu \mathrm{g} / \mathrm{mL}$ (data not shown). The antimicrobial action of nanomaterials is typically assigned to their composition, size, shape, and surface corona [33]. Unlike the AgNPs, the as-synthesized AuNPs showed a clear surface layer, which might have resulted from a surface coating of components in the WCE that participated in the NPs formation. In addition, the AuNPs were on average approximately 3-fold larger than the AgNPs. Therefore, it can be concluded that the loss of antibacterial activity might have resulted from the surface modification of the AuNPs and their large size.

\section{Conclusion}

Recently, the biological synthesis of metal NPs has been extensively studied to produce biocompatible NPs using a cost-effective and eco-friendly method. Plants or their extracts can be used in large-scale production of NPs. However, to the best of our knowledge, all phytosynthetic methods have different reaction conditions for the efficient production of NPs. Therefore, the plant material must be selected before optimizing the reaction parameters. Woodchips are one of the most abundant bioresources in the world but their 


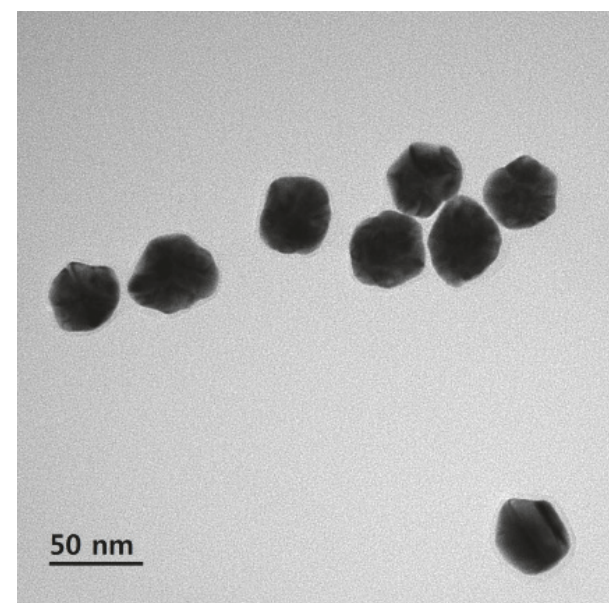

(a)

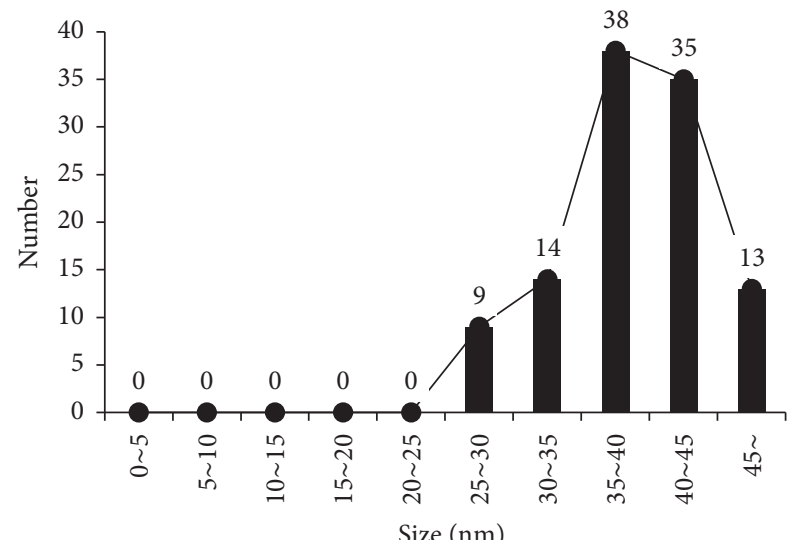

(b)

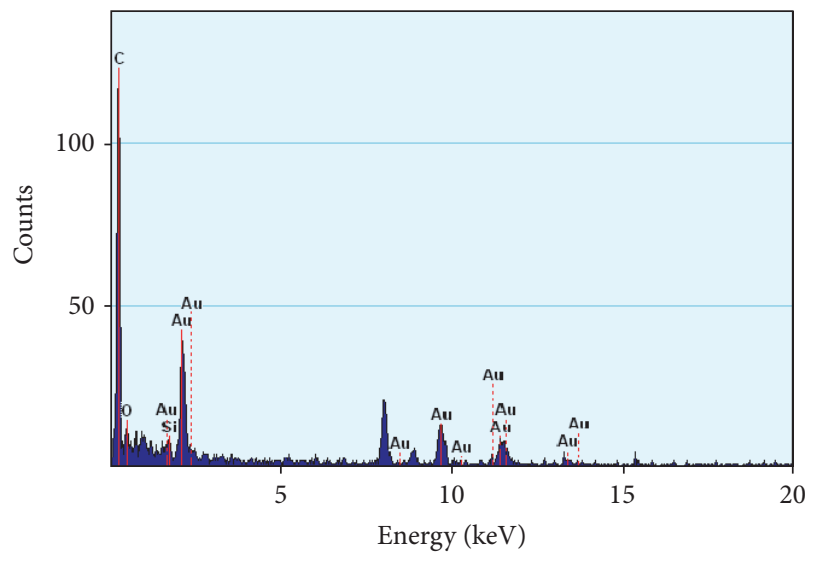

- EDX drift corrected spectrum profile

(c)

Figure 14: A representative HR-TEM image of the AuNPs (a), a particle size distribution histogram of the AuNPs determined from TEM images (b), and an EDX result of a single AuNP (c).

application in the production of high-value-added products has rarely been reported. In this study, AgNPs and AuNPs were phytosynthesized using WCE. The effects of reaction factors including the reaction $\mathrm{pH}$, concentrations of the precursor salts and WCE, and external energy inputs (both heat and light) were investigated. In addition, their antibacterial efficacy against four representative Gram-negative and Gram-positive bacterial strains was evaluated. The formation of the AgNPs was greatly affected by the reaction $\mathrm{pH}$, and the increase in the $\mathrm{pH}$ caused a blue shift in the SPR band. The increasing $\mathrm{pH}$ also sharpened the band, which indicates a narrow size distribution of the NPs. The WCE concentration was also important for increasing the productivity of the phytosynthesis of the AgNPs. In addition, the light energy input further enhanced the formation of the NPs. The effects of the reaction parameters for the phytosynthesis of AuNPs were somewhat different from those of AgNPs. The most important factors for the AuNP synthesis were reaction $\mathrm{pH}$ and the precursor concentration. Evident blue shifts occurred with the increasing reaction $\mathrm{pH}$, temperature, and strength of visible light, indicating the complexity of the reaction. Compared with the phytosynthesis of AgNPs, the results for AuNPs indicate that more research is required to enhance the reaction rate for high-quantity production of the NPs. The AgNPs and AuNPs were spherical and irregular in shape, respectively. On average, the AuNPs $(39 \mathrm{~nm})$ were larger than the AgNPs $(13 \mathrm{~nm})$. The crystallinity of both NPs was determined by analyzing TEM images and XRD patterns. The phytosynthesized AgNPs showed antibacterial activity against the tested bacterial strains, thus indicating that the AgNPs could be used as a biocidal agent. However, the phytosynthesized AuNPs did not exhibit the bactericidal effect, which might have been caused by surface modification of the NPs by components from the WCE and their large size. 


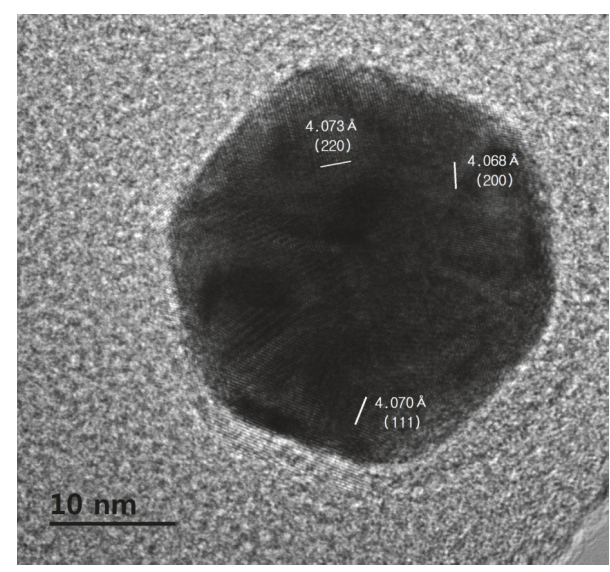

(a)

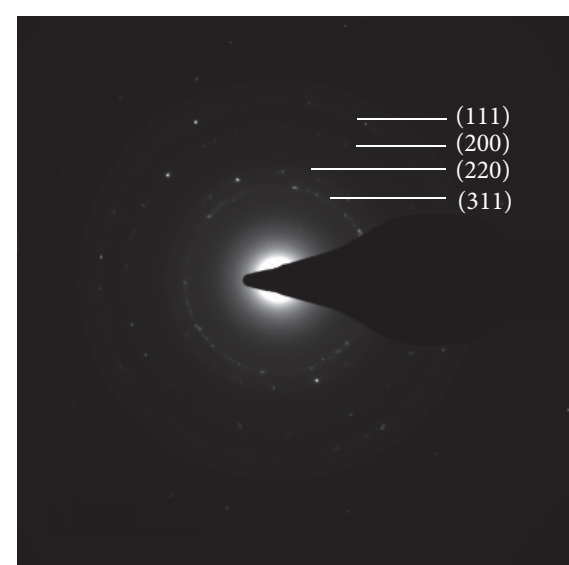

(b)

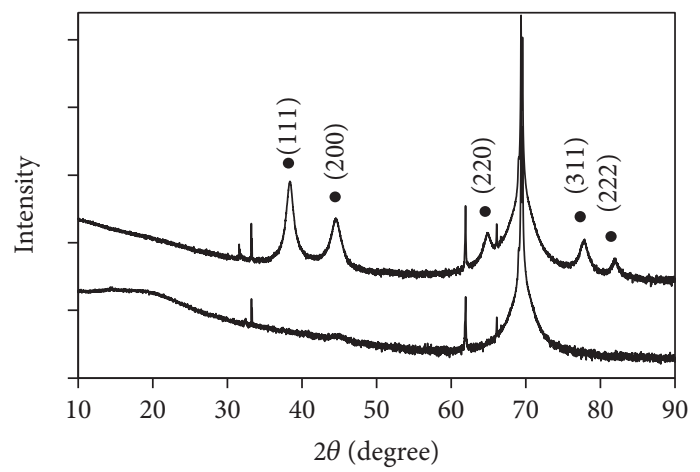

(c)

FIGURE 15: HR-TEM image of a single polycrystalline AuNP (a), SAED pattern with the diffraction rings indexed with reference to fcc gold, and XRD patterns of WCE alone (lower line) and the as-synthesized AuNPs (upper line) (c).

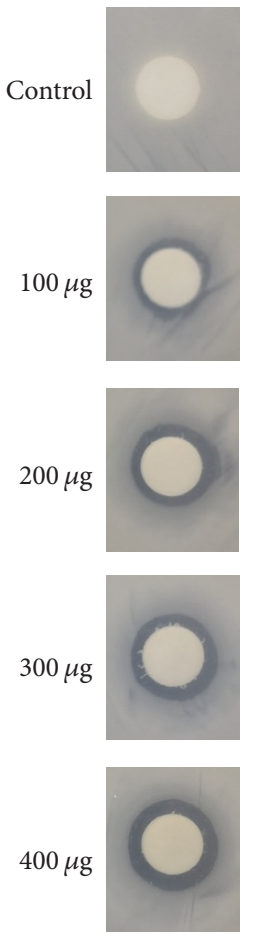

(a)
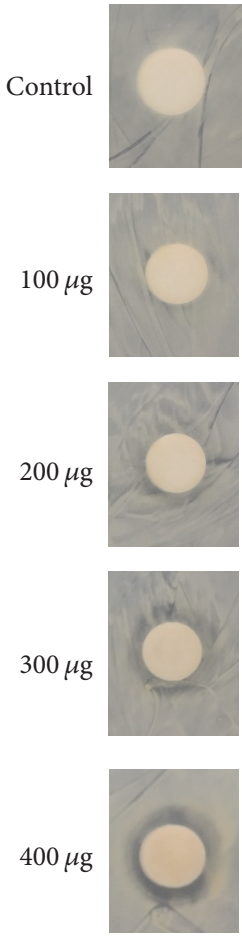

(b)
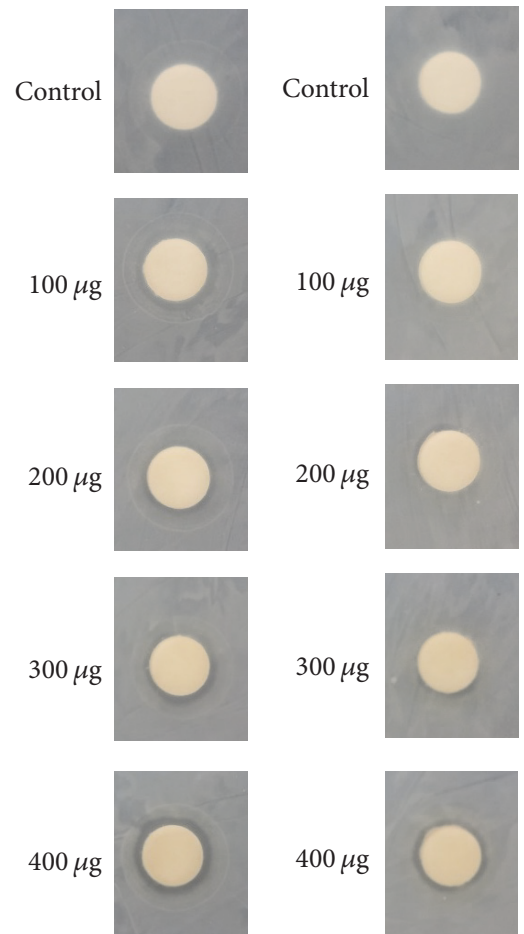

(c)

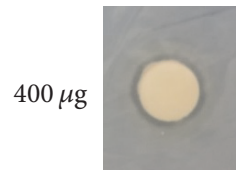

(d)

FIGURE 16: Antibacterial efficacy of the as-synthesized AgNP against four representative Gram-positive and Gram-negative strains. B. subtilis (a), S. aureus (b), S. typhimurium (c), and E. coli (d). 
In this study, WCE was chosen for the phytosynthesis of AgNPs and AuNPs because it is a ubiquitous, inexpensive biomass. Although various plant extracts have been successfully used to synthesize NPs, our results demonstrate that the optimized phytosynthesis of both NPs using WCE could be one of the most effective methods considering the synthesis rate, conversion yield, cost effectiveness, and simplicity of the process.

\section{Conflicts of Interest}

The authors declare that they have no conflicts of interest.

\section{Acknowledgments}

This study was financially supported by the National Research Foundation of Korea (Grant no. NRF-2015M2A2A6A03045350).

\section{References}

[1] K. N. Thakkar, S. S. Mhatre, and R. Y. Parikh, "Biological synthesis of metallic nanoparticles," Nanomedicine: Nanotechnology, Biology, and Medicine, vol. 6, no. 2, pp. 257-262, 2010.

[2] A. B. Moghaddam, F. Namvar, M. Moniri, P. M. Tahir, S. Azizi, and R. Mohamad, "Nanoparticles biosynthesized by fungi and yeast: a review of their preparation, properties, and medical applications," Molecules, vol. 20, no. 9, pp. 16540-16565, 2015.

[3] R. Mohammadinejad, S. Karimi, S. Iravani, and R. S. Varma, "Plant-derived nanostructures: types and applications," Green Chem., vol. 18, no. 1, pp. 20-52, 2016.

[4] B. Fadeel and A. E. Garcia-Bennett, "Better safe than sorry: understanding the toxicological properties of inorganic nanoparticles manufactured for biomedical applications," Advanced Drug Delivery Reviews, vol. 62, no. 3, pp. 362-374, 2010.

[5] W. C. Chan and S. Nie, "Quantum dot bioconjugates for ultrasensitive non-isotopic detection," Science, vol. 281, no. 5385, pp. 2016-2018, 1998.

[6] F. Tian, A. Prina-Mello, G. Estrada et al., "A novel assay for the quantification of internalized nanoparticles in macrophages," Nanotoxicology, vol. 2, no. 4, pp. 232-242, 2008.

[7] D. Cui, F. Tian, S. R. Coyer et al., "Effects of antisense-mycconjugated single-walled carbon nanotubes on HL-60 cells," Journal of Nanoscience and Nanotechnology, vol. 7, no. 4-5, pp. 1639-1646, 2007.

[8] D. Pantarotto, C. D. Partidos, J. Hoebeke et al., "Immunization with peptide-functionalized carbon nanotubes enhances virusspecific neutralizing antibody responses," Chemistry and Biology, vol. 10, no. 10, pp. 961-966, 2003.

[9] R. Weissleder, G. Elizondo, J. Wittenberg, C. A. Rabito, H. H. Bengele, and L. Josephson, "Ultrasmall superparamagnetic iron oxide: characterization of a new class of contrast agents for MR imaging," Radiology, vol. 175, no. 2, pp. 489-493, 1990.

[10] V. A. Basiuk and E. V. Basiuk, Green Processes for Nanotechnology, Springer International Publishing, Cham, Germany, 2015.

[11] K. B. Narayanan and N. Sakthivel, "Biological synthesis of metal nanoparticles by microbes," Advances in Colloid and Interface Science, vol. 156, no. 1-2, pp. 1-13, 2010.

[12] M. I. Husseiny, M. A. El-Aziz, Y. Badr, and M. A. Mahmoud, "Biosynthesis of gold nanoparticles using Pseudomonas aeruginosa," Spectrochimica Acta A: Molecular and Biomolecular Spectroscopy, vol. 67, no. 3-4, pp. 1003-1006, 2007.

[13] G. S. Dhillon, S. K. Brar, S. Kaur, and M. Verma, "Green approach for nanoparticle biosynthesis by fungi: current trends and applications," Critical Reviews in Biotechnology, vol. 32, no. 1, pp. 49-73, 2012.

[14] A. Ahmad, S. Senapati, M. I. Khan, R. Kumar, and M. Sastry, "Extracellular biosynthesis of monodisperse gold nanoparticles by a novel extremophilic actinomycete, Thermomonospora sp.," Langmuir, vol. 19, no. 8, pp. 3550-3553, 2003.

[15] M. Kowshik, S. Ashtaputre, S. Kharrazi et al., "Extracellular synthesis of silver nanoparticles by a silver-tolerant yeast strain MKY3," Nanotechnology, vol. 14, no. 1, pp. 95-100, 2003.

[16] C. K. Jeong, I. Kim, K.-I. Park et al., "Virus-directed design of a flexible BaTiO3 nanogenerator," ACS Nano, vol. 7, no. 12, pp. 11016-11025, 2013.

[17] M. Noruzi, "Biosynthesis of gold nanoparticles using plant extracts," Bioprocess and Biosystems Engineering, vol. 38, no. 1, pp. 1-14, 2015.

[18] S. S. Shankar, A. Rai, A. Ahmad, and M. Sastry, "Rapid synthesis of $\mathrm{Au}, \mathrm{Ag}$, and bimetallic Au core-Ag shell nanoparticles using Neem (Azadirachta indica) leaf broth," Journal of Colloid and Interface Science, vol. 275, no. 2, pp. 496-502, 2004.

[19] S. Iravani, "Green synthesis of metal nanoparticles using plants," Green Chemistry, vol. 13, no. 10, pp. 2638-2650, 2011.

[20] M. H. Joe, H. T. Jeong, H. M. Lee et al., Green synthesis of silver and gold nanoparticles using hot water extract of mixed woodchip powder and their antibacterial efficacy [Unpublished M.S. thesis], Chonnam National University, Gwangju, Republic of Korea, Retrieved from http://ndsl.kr/ndsl/search/detail/article/ articleSearchResultDetail.do?cn=DIKO0014473111.

[21] S. P. Chandran, M. Chaudhary, R. Pasricha, A. Ahmad, and M. Sastry, "Synthesis of gold nanotriangles and silver nanoparticles using Aloe vera plant extract," Biotechnology Progress, vol. 22, no. 2, pp. 577-583, 2006.

[22] N. Ramezani, Z. Ehsanfar, and F. Shamsa, "Screening of Medicinal Plant Methanol Extracts for the Synthesis of Gold Nanoparticles by Their Reducing Potential," Zeitschrift Für Naturforsch. B, vol. 63, article 903, 2008.

[23] A. N. Mishra, S. Bhadauria, M. S. Gaur, R. Pasricha, and B. S. Kushwah, "Synthesis of gold nanoparticles by leaves of zero-calorie sweetener herb (Stevia rebaudiana)and their nanoscopic characterization by spectroscopy and microscopy," International Journal of Green Nanotechnology: Physics and Chemistry, vol. 1, no. 2, pp. 118-124, 2010.

[24] M. S. Akhtar, J. Panwar, and Y.-S. Yun, "Biogenic synthesis of metallic nanoparticles by plant extracts," ACS Sustainable Chemistry and Engineering, vol. 1, no. 6, pp. 591-602, 2013.

[25] D. Andreescu, C. Eastman, K. Balantrapu, and D. V. Goia, "A simple route for manufacturing highly dispersed silver nanoparticles," Journal of Materials Research, vol. 22, no. 9, pp. 2488-2496, 2007.

[26] Z. Sadowski, I. H. Maliszewska, B. Grochowalska, I. Polowczyk, and T. Koźlecki, "Synthesis of silver nanoparticles using microorganisms," Materials Science, vol. 26, no. 2, pp. 419-424, 2008.

[27] Q. Sun, X. Cai, J. Li, M. Zheng, Z. Chen, and C.-P. Yu, "Green synthesis of silver nanoparticles using tea leaf extract and evaluation of their stability and antibacterial activity," Colloids and Surfaces A: Physicochemical and Engineering Aspects, vol. 444, pp. 226-231, 2014. 
[28] J. Y. Song, H.-K. Jang, and B. S. Kim, "Biological synthesis of gold nanoparticles using Magnolia kobus and Diopyros kaki leaf extracts," Process Biochemistry, vol. 44, no. 10, pp. 1133-1138, 2009.

[29] S. P. Dubey, M. Lahtinen, and M. Sillanpää, “Tansy fruit mediated greener synthesis of silver and gold nanoparticles," Process Biochemistry, vol. 45, no. 7, pp. 1065-1071, 2010.

[30] M. Grzelczak and L. M. Liz-Marzán, "The relevance of light in the formation of colloidal metal nanoparticles," Chemical Society Reviews, vol. 43, no. 7, pp. 2089-2097, 2014.

[31] M. Gericke and A. Pinches, "Biological synthesis of metal nanoparticles," Hydrometallurgy, vol. 83, no. 1-4, pp. 132-140, 2006.

[32] M. Sathishkumar, K. Sneha, and Y.-S. Yun, "Immobilization of silver nanoparticles synthesized using Curcuma longa tuber powder and extract on cotton cloth for bactericidal activity," Bioresource Technology, vol. 101, no. 20, pp. 7958-7965, 2010.

[33] H. K. Daima, P. R. Selvakannan, R. Shukla, S. K. Bhargava, and V. Bansal, "Fine-tuning the antimicrobial profile of biocompatible gold nanoparticles by sequential surface functionalization using polyoxometalates and lysine," PLoS ONE, vol. 8, no. 10, article e79676, 2013. 

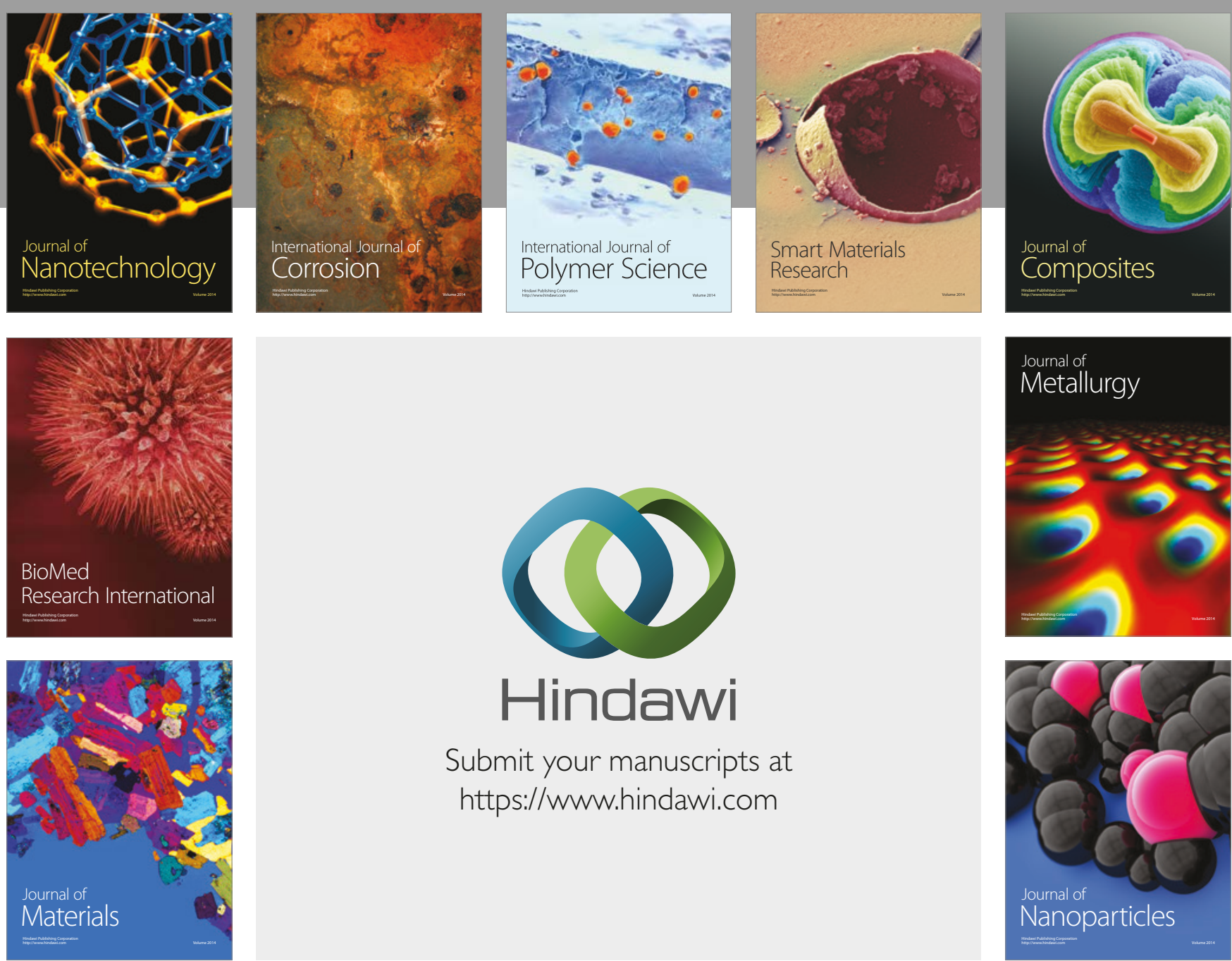

\section{Hindawi}

Submit your manuscripts at

https://www.hindawi.com
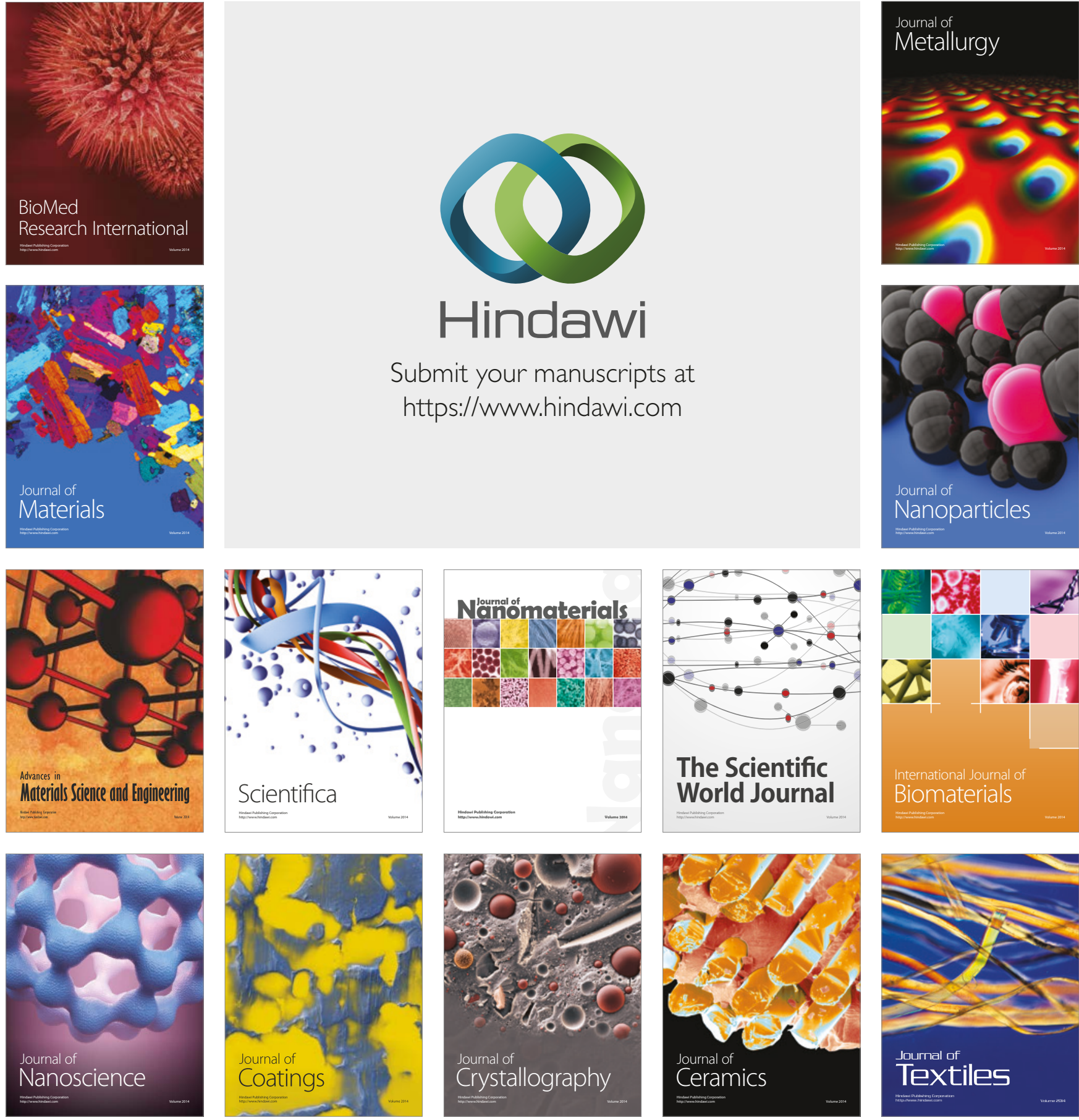

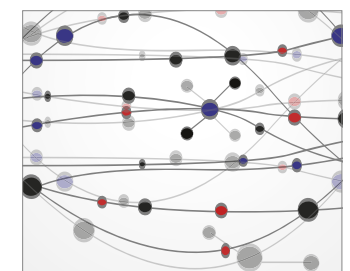

The Scientific World Journal
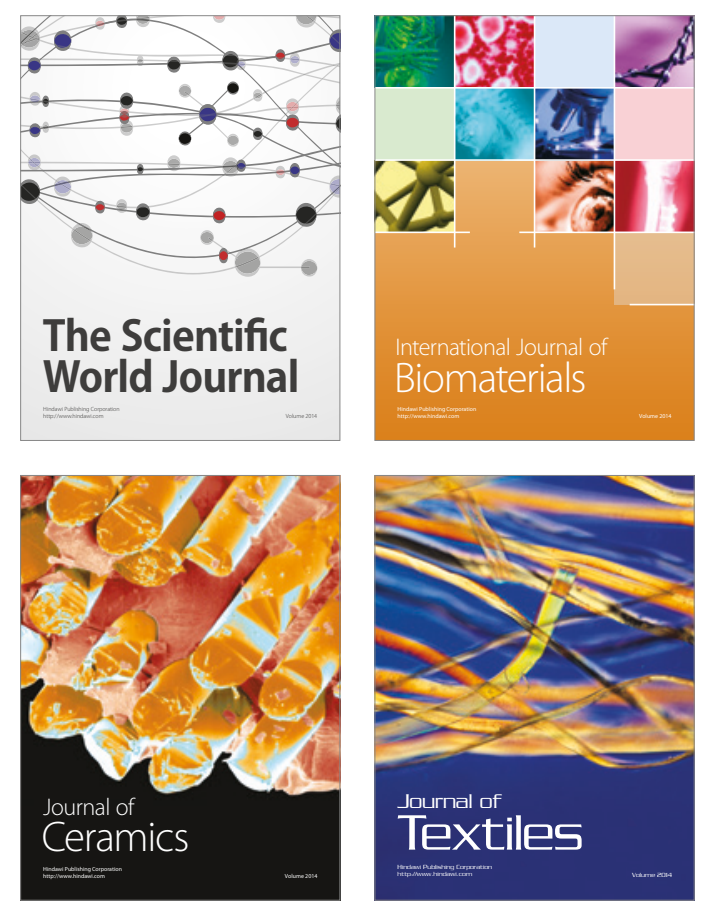